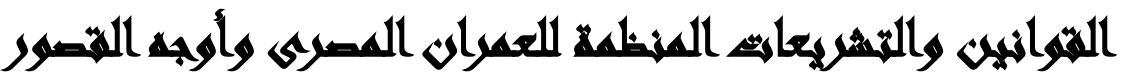

[7]

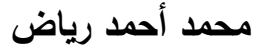 \\ قسم الهندسة المعمارية، كلية الهندسة بالمطرية، جامعة حلوان

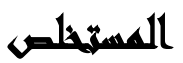

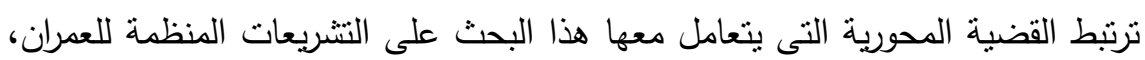

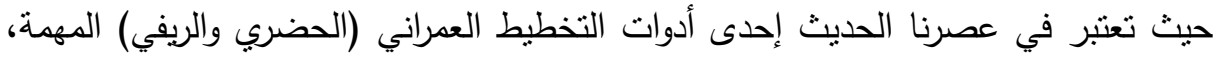

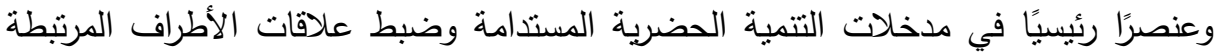

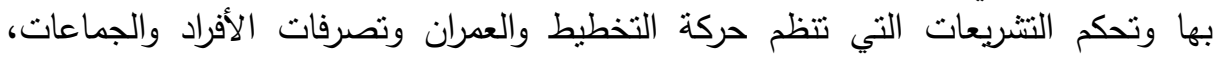

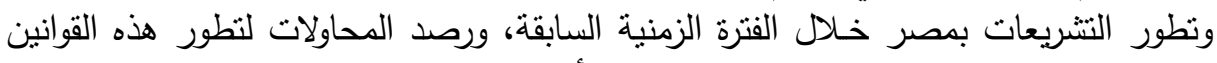

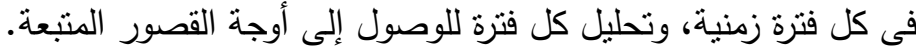

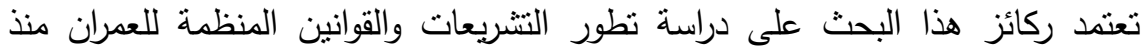

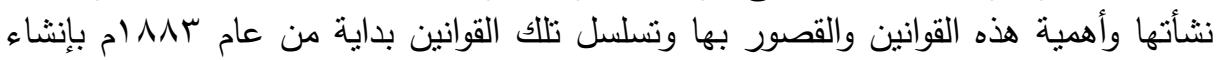

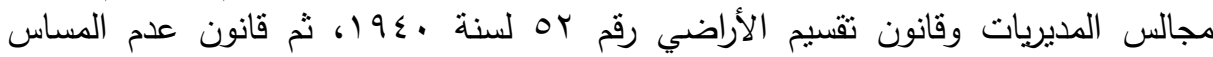

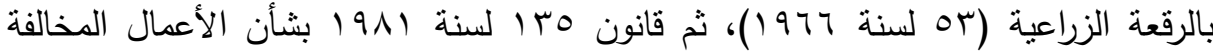

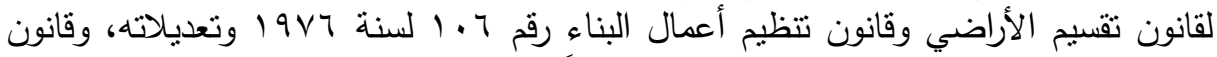

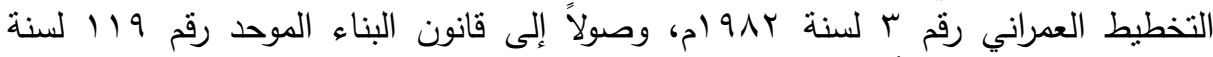

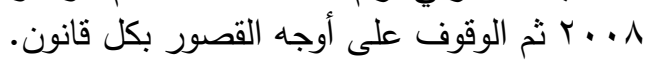

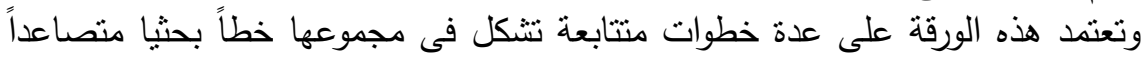

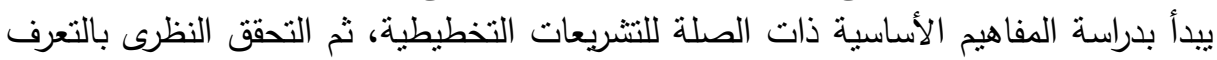

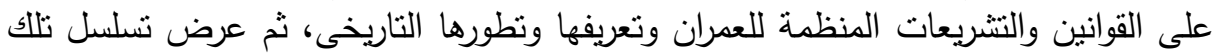

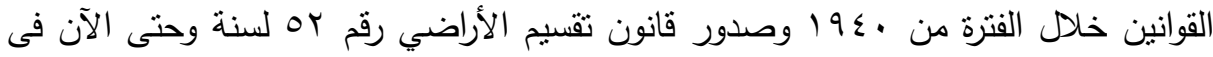

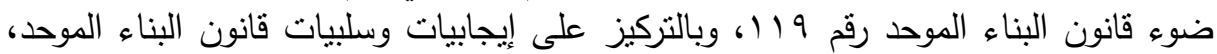

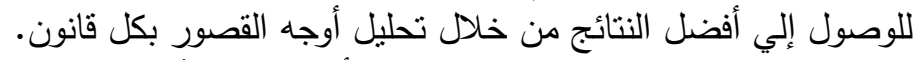

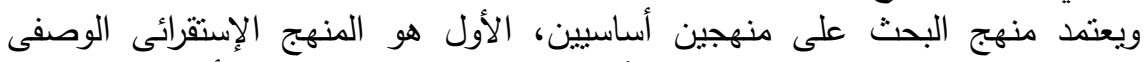

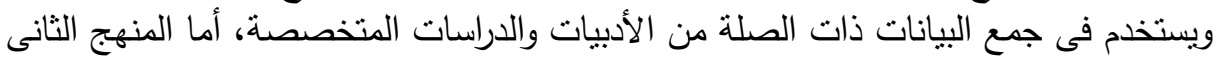

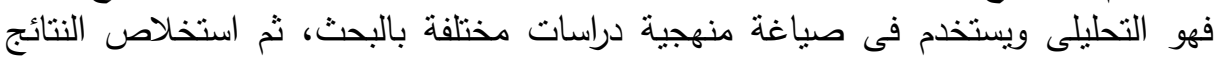

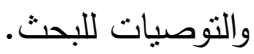
وقد إنتهى البحث إلى العديد من النتائج أهمها الوقوف على أوجه القصور بكل قانون،

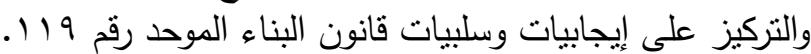

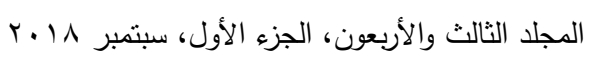


محمد أحمد رباض

الكلمات الدالة: القوانين والتتريعات المنظمة للعمران، التشريعات العمرانية، التشريعات

التخطيطية، أوجه القصور بالتنشريعات العمرانية.

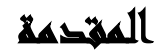

نتيجة للثورة الصناعية والنمو السريع للمدن والهجرة المستمرة من أهل الريف، انتشرت

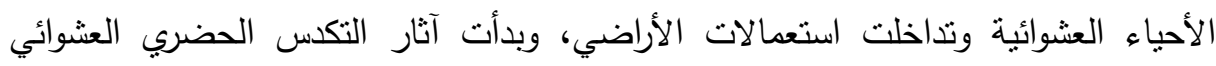

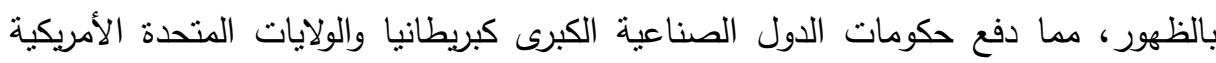
بالتنخل عن طريق سن القوانين والتشريعات التي تحد من استعمال الأفراد لملكياتهم الخاصة، وتتحكم باستعمالات الأراضي الحضرية والمباني التي تقام عليها، وتحديد خطوط محرمات

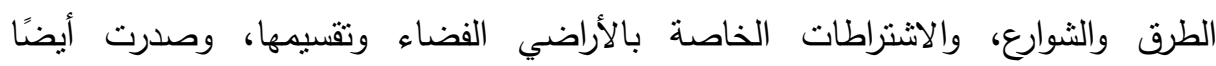

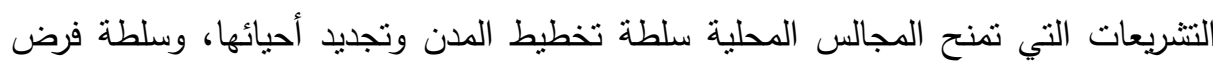
الرسوم البلدية على العقارات والمنشآت، في مقابل الخدمات التي يقدمها مجلس المدينة [1]. وتتدرج التشريعات من ناحية القوة الى ثناث مراتب: الدستور، القانون، اللائحة

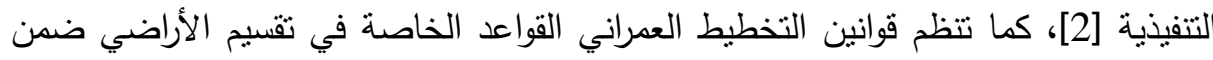
المناطق الحضرية في المدينة وفي المناطق الريفية أيضًا. وكانت المدن الألمانية والسويدية من أوائل المدن التي طبقت التبن التشريعات العمرانية في أواخر القرن التاسع عشر، لمعالجة مشاكل التكدس الحضري والأبنية العالية.

\section{أهسا اهت المهنه}

يهدف البحث الى الوقوف على أوجه القصور والإيجابيات والسلبيات للقوانين والنشريعات المنظمة للعمران بمصر (بالتركيز على قانون البناء الموحد رقم 119 ولائحته التتفيذية) وتحديداً فيما يخص المناطق الغير مخططة، وذلك لتفعيل الدور التشريعي وتتميته بما يخدم المجتع وسد منطلبات النمو والتطور الذي يواكب العصر أو تعديل القوانين والتشريعات بما

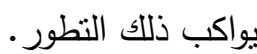




\section{هريحل المهنه}

يتكون البحث من ست نقاط رئيسية، الأولى نتعلق بالمفاهيم العامة والأساسية المرنبطة

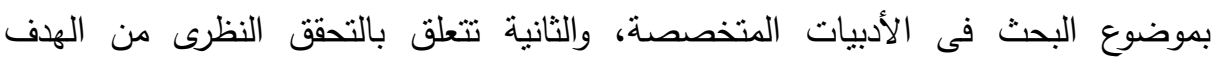

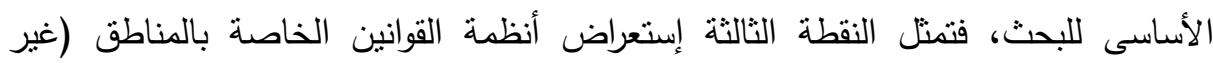
المخططة) فى الدول الغربية، وتمثل النقطة الرابعة عرض تسلسل القوانين والتشريعات المنظمة النسة

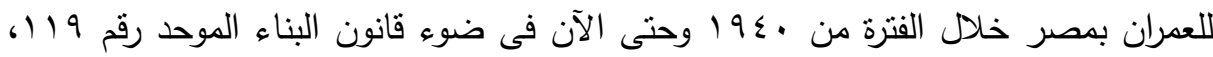

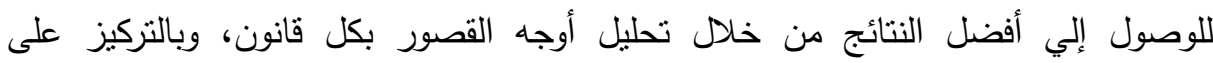

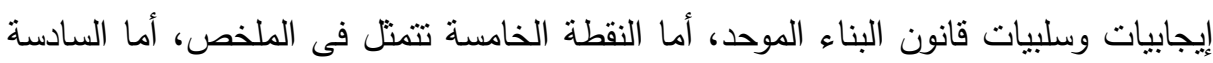
والأخيرة فنتعلق باستخلاص النتائج العامة والتوصيات.

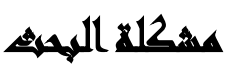

تكمن وتتمثل المشكلة الأساسية للبحث فى مصر بظهور العديد من القوانين والتتريعات

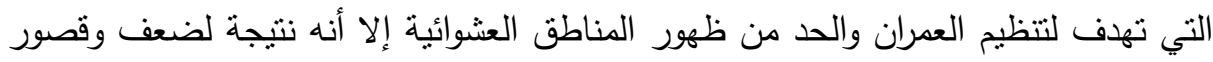

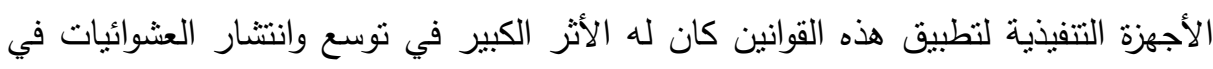
معظم المدن المصرية.

\section{مشوض الهمهي}

تتمثل الحدود المكانية للبحث فى المناطق العشوائية بمصر. أما الحدود الموضوعية فتتمنل فى عرض وتحليل القوانين والتشريعات التي تهدف لنظيم العمران والحد من ظهور

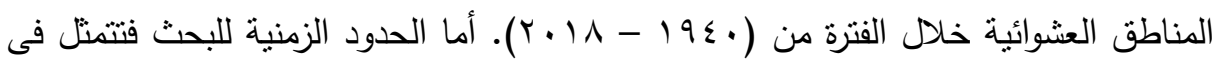
الفترة التاريخية الحالية.

\section{هنهمج الهمبش}

يتبنى البحث اطار تحليلا يعتد على استخدام منهجين أساسيين، المنهج الأول وهو المنهج الإستقرائى الوصفى (Descriptive Approach) ويستخدم فى جمع البيانات ذات الصلة من الأدبيات والدراسات المتخصصة، كما يستخدم فى الاثبات النظرى لصحة فرضية

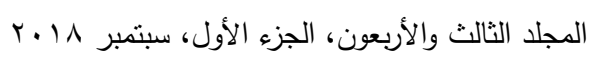


البحث، أما المنهج الثانى فهو التحليلى (Analytical) ويستخدم فى صياغة وتدقيق وعرض

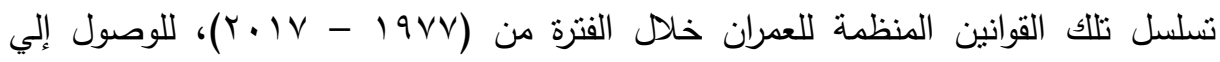
السياسية التشريعية التي انتهجتها كل مرحلة وتحليلها للوصول إلي أفضل النتائج من خلال تحليل أوجه القصور بكل قانون.

تشريعات العمران: تشريعات العمران هي مجموعة القواعد القانونية المكتوبة الصادرة عن السلطة المختصة (وهي السلطة التشريعية) التي تحكم وتضبط عملية التخطيط العمراني بكافة

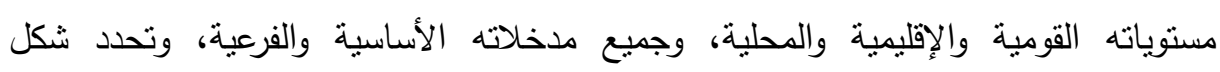

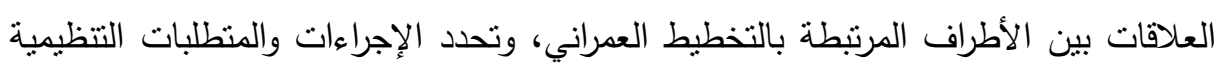

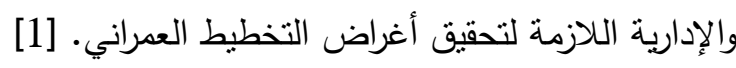
التشريعات والقوانين المنظمة للعمران هي الإطار اللازم لنمو العمران حيث توجه النمو

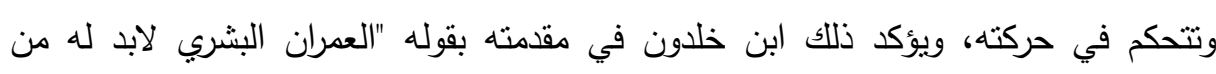

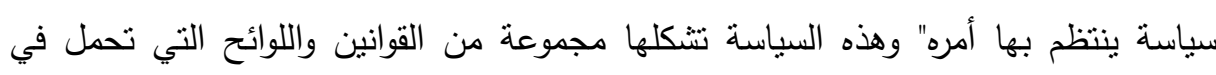
طياتها الكثير من القيم والمعايير التخطيطية التي من شأنها تتظيم نمو العمران في المدن.

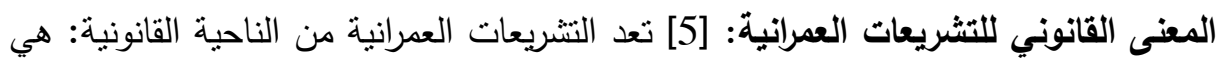

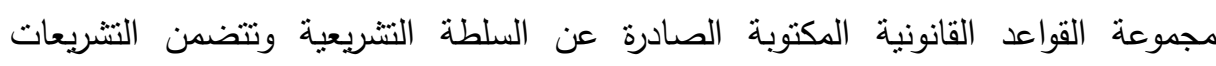
العمرانية من الناحية القانونية المحاور الرئيسية التالية: - تبني السياسات والخطط والبرامج التخطيطية الاستراتيجية ، التي تضعها السلطة السياسية كمنطلق وموجه أساسي لعملية التخطيط العمراني على المستوى القومي. - تحديد الجهات أو السلطات المختصة والمسؤلة عن عملية التخطيط العمراني. - وضع مجموعة القواعد القانونية الموضوعية، والتي تعد تقنينا لمجمل المعايير والضوابط عليه التخطيطية والأنظمة العمرانية العلمية والمنهجية، الواجب الالتزام بها. - تحدد طبيعة العلاقات والأدوار بين كافة الأطراف المرتبطة بعملية التخطيط العمراني.

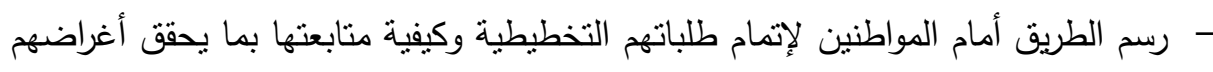

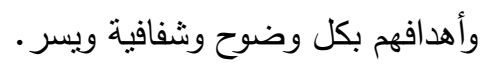




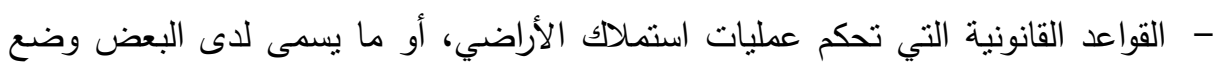

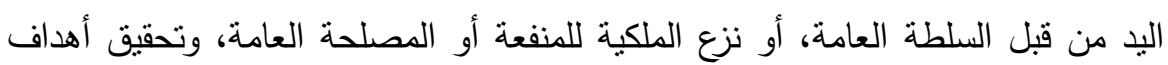

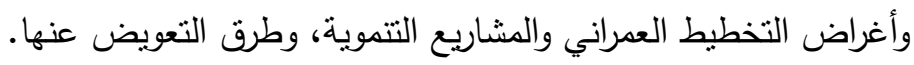
- القواعد المنظمة لأعمال الرقابة التخطيطية واجراءاتها. - مجموعة النصوص المتعلقة بالمخالفات التخطيطية، والعقوبات المترتبة على نلك لكاهل

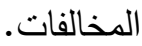

المفهوم التخطيطي للتشريعات العمرانية: [3] يختلف مفهوم التشريعات العمرانية من الناحية

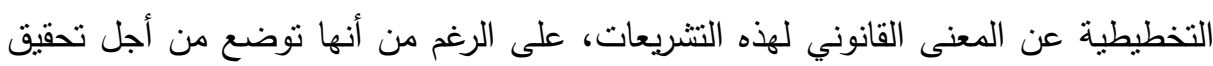

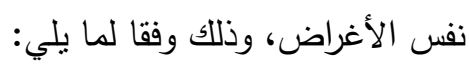
- - هي مجموعة الأسس والقواعد الواجب مراعاتها عند وضع خطط وبرامج التخطيط العمراني والتي تشمل كافة الأبعاد التخطيطية (العمرانية والاقتصادية والاجتماعية والبيئية .. الخ).

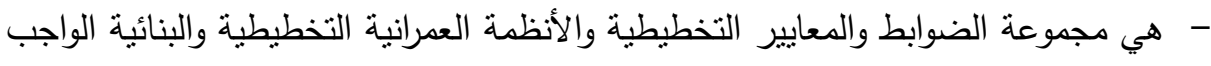
الالتزام بها، لتنفيذ مشاريع التخطيط العمراني، على كافة مسنوياته ومخططاته الإستراتيجية

$$
\text { العامة والتفصيلية. }
$$

- هي مجموعة القواعد التخطيطية العلمية التي يرجع إليها المخططون عند تتفيذ الدراسات

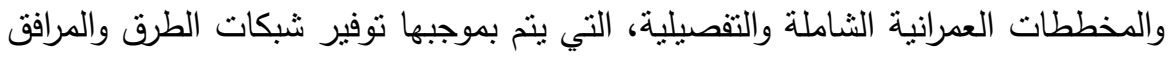
والخدمات العامة، ومراعاة الاعتبارات السكانية والبيئية، والسلامة العامة، وضمان لونئ إقامة

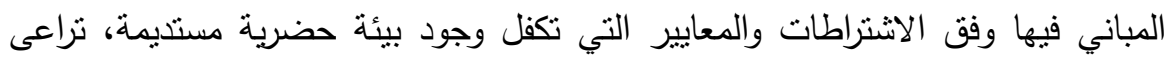
فيها الخدمات الصحية والجمالية العامة. 


\section{قوانين التخطيط العمراني لبعض الدول الغربية:}

القوانين والأنظمة العمرانية في المملكة المتحدة: وضعت المملكة المتحدة نظام تخطيط المدن والقرى لتخطيط استعمال الأراضي كنظام لتحقيق التوازن بين التتمية الاقتصادية

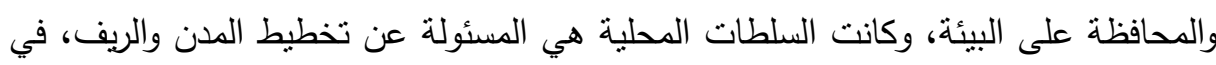

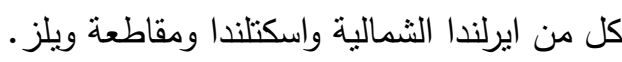
وتعود جذور الأنظمة التخطيطية في المملكة المتحدة إلى فترة الحرب العالمية الثانية،

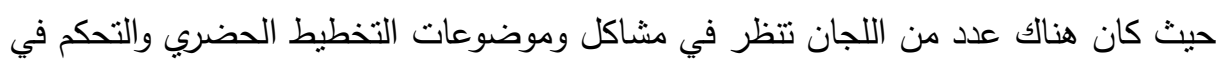
التنمية وهي: - لجنة بارلو Barlow لنوزيع سكن العمال • ع 19 ـ.

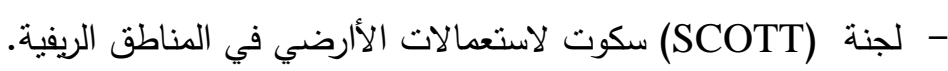

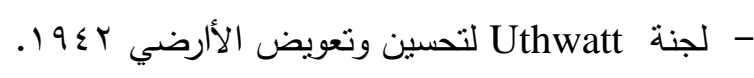
وبعد الحرب ازدادت المخاوف الناتجة عن الزحف العمراني والتلوث البيئي، فبدأ المفكرين بالتخطيط الحضري امثال ابنزار هوارد وغيره، بإعداد بعض الخطط والتقارير، فوضع باتريك أنيك

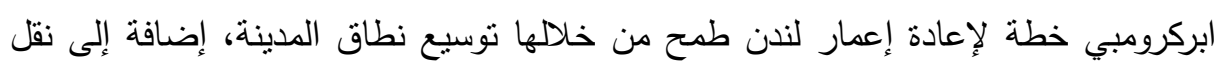
1, 1, مليون شخص من لندن إلى مدن جديده ، وأدت جهود أولئك المفكرين عموما إلى ظهور :

$$
\begin{aligned}
& \text { - تقرير REITH حول المدن الجديدة. }
\end{aligned}
$$

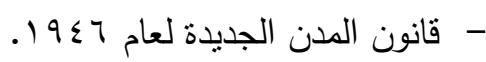

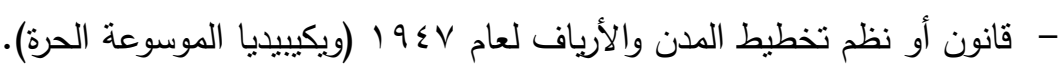

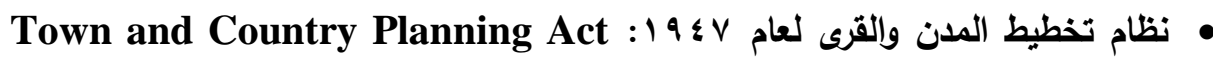

[5] وضع عدد من الأنظمة والتشريعات الجزئية التي تتعرض للتخطيط العمراني في

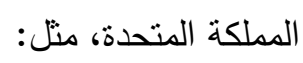

Land Settlement (Facilities) Act نظام الخدمات العامة للمستوطنات البشرية -

- التظيم العام لسلطات التخطيط ومستوياته والمخططات اللازمة للتتمية عام rبو إلا أن نظام تخطيط المدن والقرى لعام V\& 19 يعتبر أول نظام شامل للتخطيط العمراني في 
المملكة المتحدة والمناطق التابعة لها، الذي تم بموجبه وضع المعايير التي تحدد نوعية التتمية التي تتطلب إذن أو تصريح تخطيطي من قبل سلطات التخطبط المحلية (وهي المجلس البلاي) حيث تضمن النظام أصلا، تعريف التنمية ومتطلباتها التخطيطية، وبالتالي ما إذا كانت تللك التتمية بحاجة إلى تصريح تخطيطي أم لا.

- - كما شمل النظام التحكم بتتمية كافة المباني، وأية تغييرات في المواد المستعملة فيها. • نظام تخطيط المدن والقرى لعام • 199 وما بعدها: مع التطور الحضري والتتموي الذي شيدته المملكة المتحدة في الفترة التالية للحرب العالمية الثانية تعاقبت التعديلات على نظام تخطيط المدن والقرى لعامV§ 19 وكان أهمها نظام عام ، 199 الذى تم بموجبه تحديد سلطات التخطيط، وخطط التتمية، ومستوياتها المحلية وعلى مستوى الهخطط الهيكلي وتصنيف استعمالات المناطق والأراضي، واشتمل على فصل خاص بموضوع استملاك الأراضي لأغراض التتمية، وتحديد الأضرار التي قد تتجم عن عمليات التتمية وأحكام التعويض عنها، والكثير من القضايا التخطيطية الرئيسية والفرعية، وقد جرى تعديل نظام

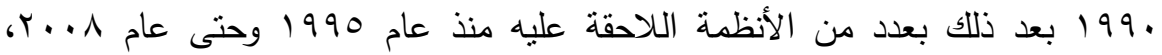

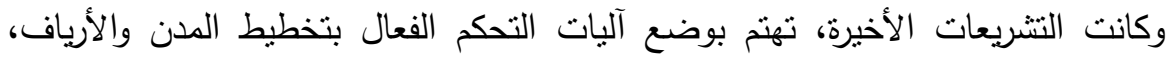
وتولي اهتماما خاصا بالأبعاد البيئية لعمليات ومشاريع التتمية الحضرية، وتمنح تنهيلات خاصة للمشروعات التتموية التي تحرص على المحافظة على مصادر الطاقة وتعتمد نظم الطاقة البديلة والمتجدة، وذلك بمنحها تسهيلات خاصة فيما يتعلق بالتصاريح التخطيطية اللازمة لتتفيذها.

\section{قوانين التخطيط العمراني في الولايات المتحدة الأمريكية [13] :}

- كان صدور أول قانون لتنظيم المباني في الولايات المتحدة الأمريكية في مدينة نبويورك

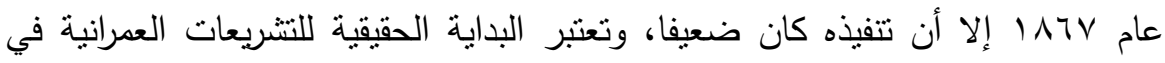

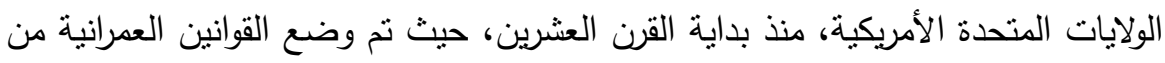

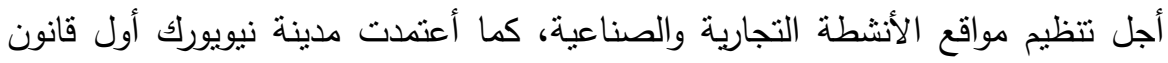
شامل عام 1917، بثأن العمران يتحكم بتقسيم المناطق وتصنيف استعمالاتها، بعد ما

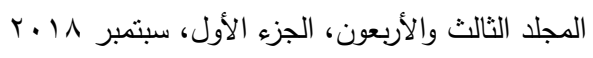


كانت اللوائح الأولية التي وضعت في وقت مبكر تتعلق بحماية الملكية، والحفاظ على الخصائص الرئيسية المنمتلة في الإضاءة والتهوية فقط.

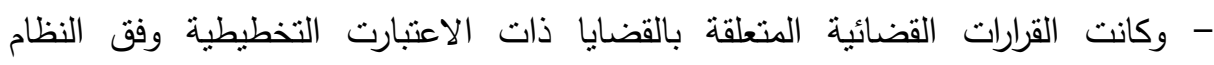
الأمريكي، تتحول من اجتهادات قضائية، إلى رمز مهم ومن ثم إلى مبادئ علمية

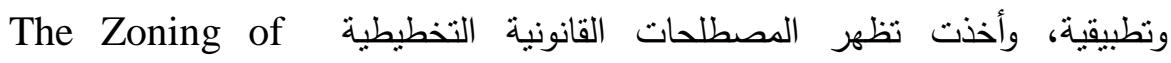
America

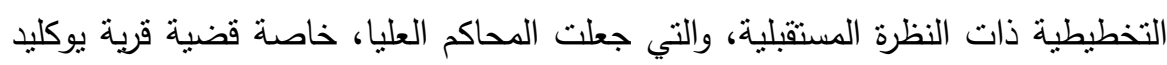

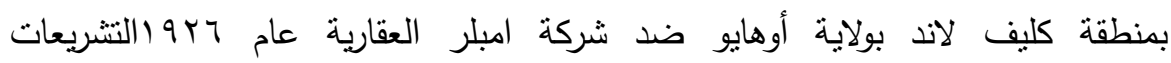
التخطيطية وقوانين استعمالات الأراضي تتطور لتصل إلى وضع ضوابط ومعايير المناطق

[5]. [5 التجميلية

- وبموجب التشريعات العمرانية الحديثة في نيويورك، صنفت استعمالات الأراضي إلى ثلاثة

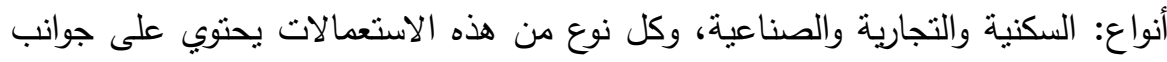
أكثر تحديدا وفقا لنوع التتمية مثل (نوعية المباني، وارتفاعاتها، ونسبة التغطية البنائية..)، واعتبرت بذلك التشريعات العمرانية إحدى الأدوات الهامة للحفاظ على الطابع العمراني للمدينة. - ـ ولكن في بعض الولايات الأخرى مثل ولاية شيكاغو، اعتبرت قوانين التخطيط العمراني من

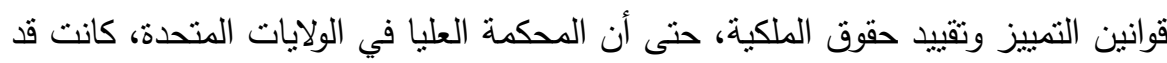
أصدرت حكما ضد منل هذه القوانين في عام التتريعات العمرانية (قوانين التمبيز آنذاكئ). - وعلى العموم فإن الدستور الأمريكي يعطي صلاحية التخطيط العمراني لحكومات الولايات وبالتالي يكون لكل ولاية صلاحية إصدار القوانين والتشريعات المتعلقة بالتخطيط العمراني ضمن ولايتها، بينما يكون للحكومة الإتحادية الصلاحية بالنسبة للقضايا المرتبطة بموضوع بلهن التخطيط على المستوى القومي ومن بينها تخطيط شبكة الطرق العابرة والواصلة بين

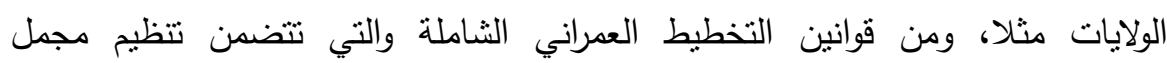
موضوعات وعناصر التخطيط العمراني، (قانون تخطيط وتقسيم الأارضي) في كاليفورنيا. (THE PLANNING AND ZONING LAW) 
القوانين المنظمة للعمران بمصر (الفترة من • ؛ 19 م حتى الآن): وتعد مصر

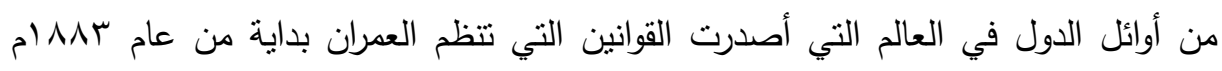

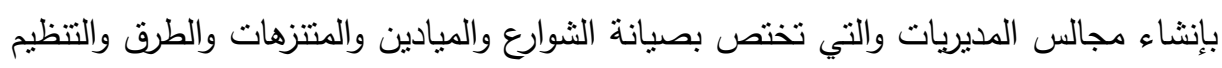
والمياه والإنارة والأسواق وأعمال المرافق والإنكان ومساعدة الفقراء.

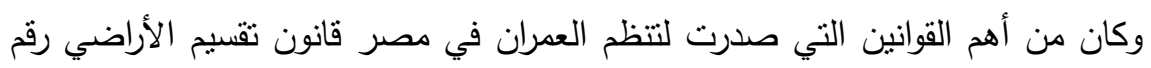

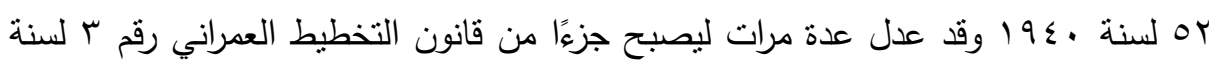

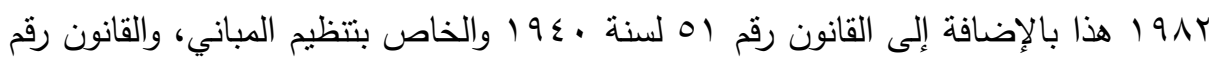

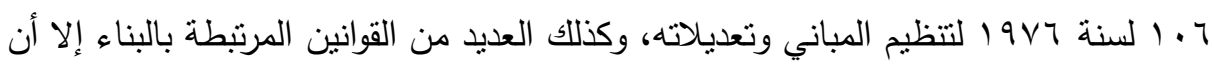

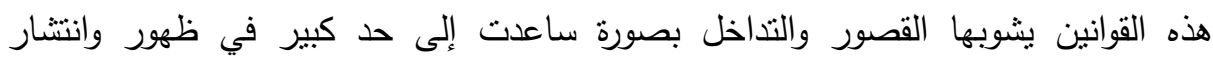

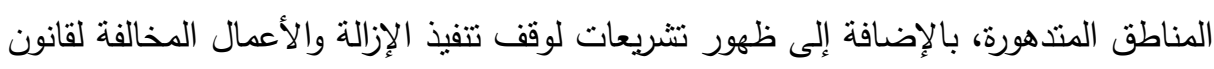

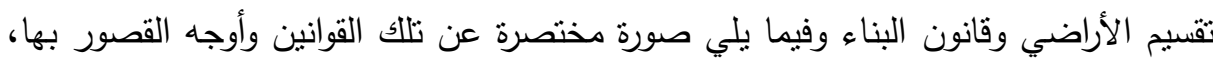

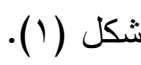

\section{القوانين والتمريعات المنظمة للعمران}

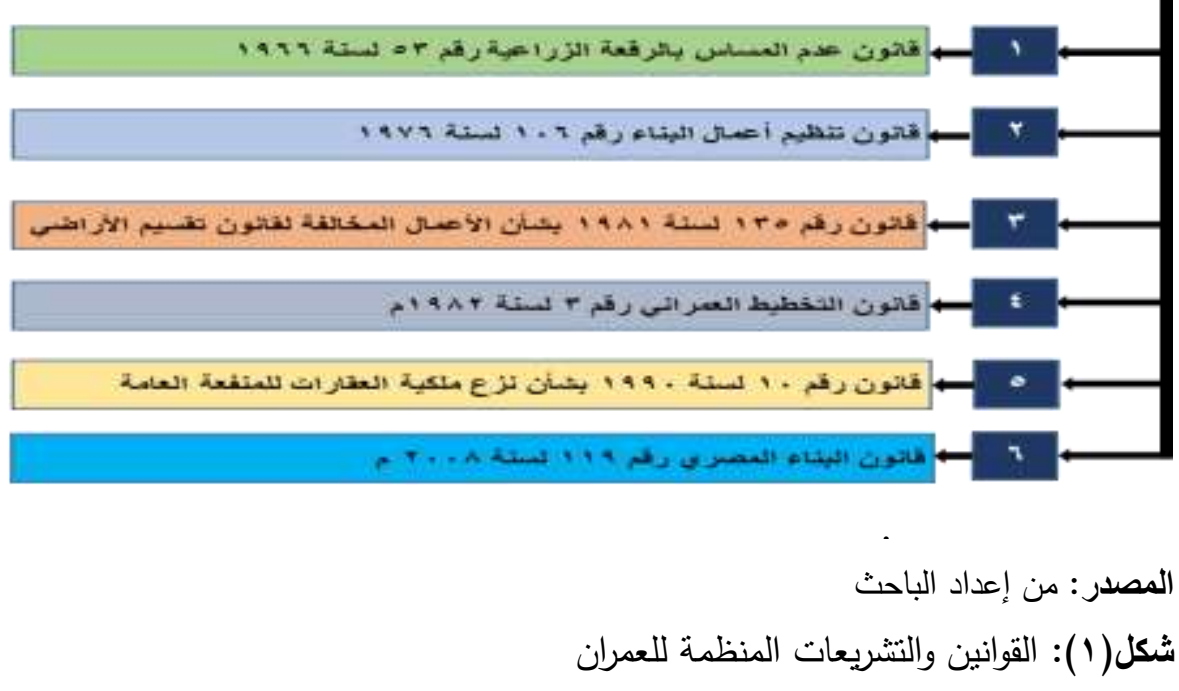


قانون (rه لسنة צ797): [6] نبذه من أحكام القانون ومهامه: صدر هذا القانون للمحافظة علي الأراضي الزراعية حيث أن ما يقرب من • 9\% من المناطق العشوائية أقيم

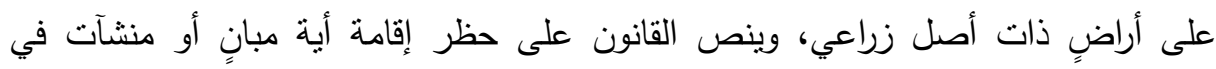

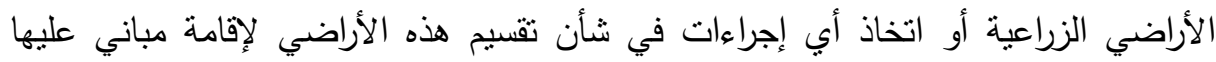
ويعتبر في حكم الأراضي الزراعية جميع الأراضي البور القابلة للزراعة. وقد استثنى القانون كلاً من:

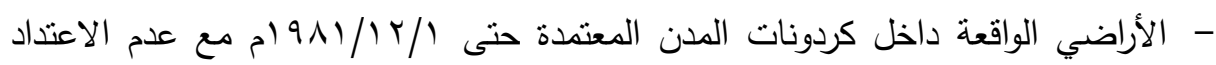

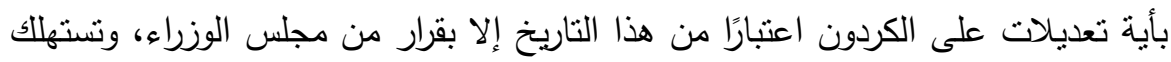
الأراضي الزراعية الواقعة داخل الكردون خلال عثرين عامًا وتقدم مديريات الزراعة خطة اعنة بأولويات الاستهلالك. - الأراضي الواقعة في نطاق الحيز العمراني للقرى والذي يصدر بتحديده قرار من وزير الزراعة بالاتفاق مع وزير التعمير (وهنا يشنرط أن يكون قد أعد حيز عمراني للقرية وتم اعتماده). - الأراضي التي تقيم عليها الحكومة مشروعات ذات نفع عام بشرط موافقة وزير الزراعة مثل

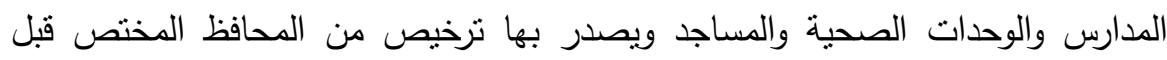
البدء في إقامة أية مبانٍ أو منشآت أو مشروعات ويصدر بتحديد شروط وإجراءات منح هذا الترخيص قرار من وزير الزراعة بالاتفاق مع وزير التعمير.

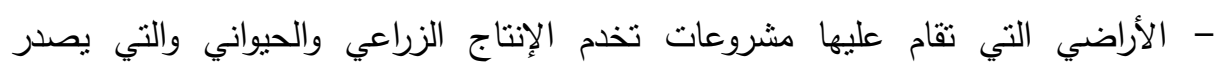
بتحديدها قرار من وزير الزراعة (كمزارع الدواجن، ومعالف تسمين المواشي، ومصانع

- الأراضي الواقعة بزمام القرية والتي يقيم عليها المالك سكنًا خاصًا به أو مبنى خاص يخدم

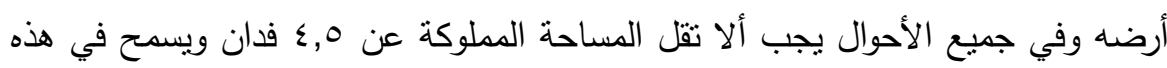
الحالة بالبناء على ما يساوي قيراطين ( .0م مبح). 
أوجه القصور في القانون (به لسنة 974 (م): على الرغم من وجود قانون حماية الأراضي

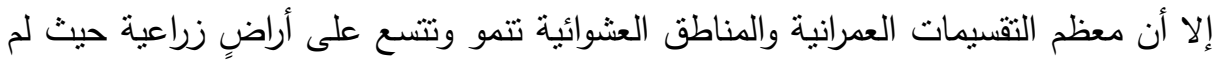

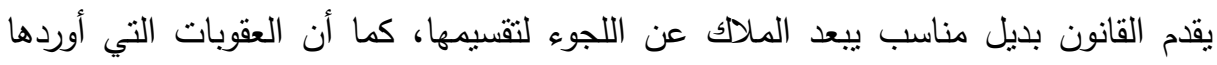

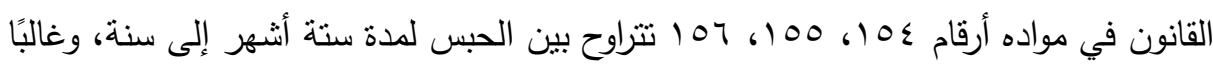

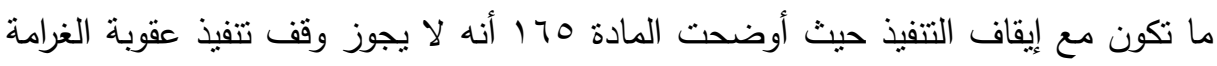

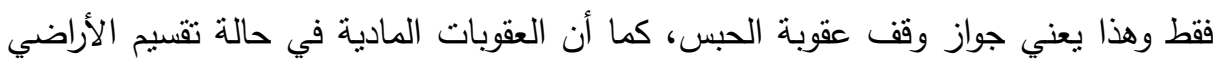

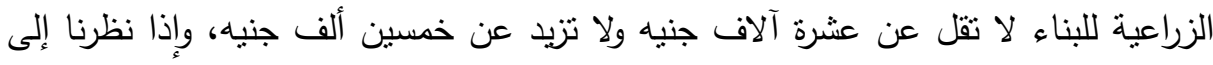

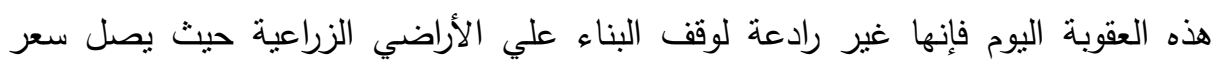

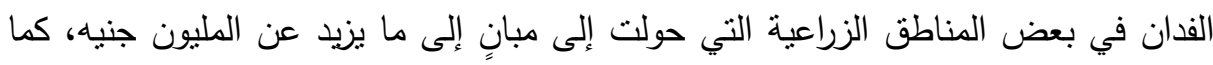

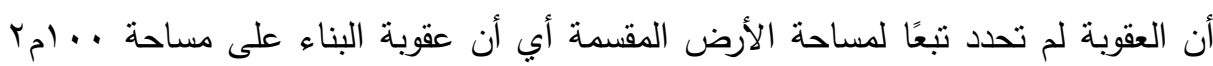

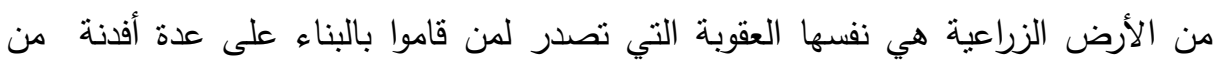

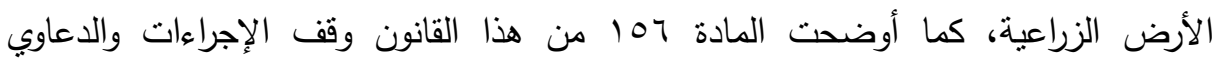

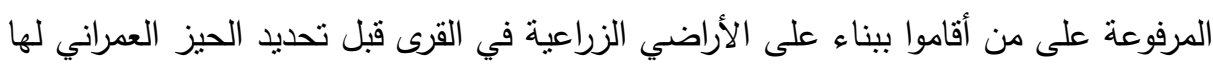

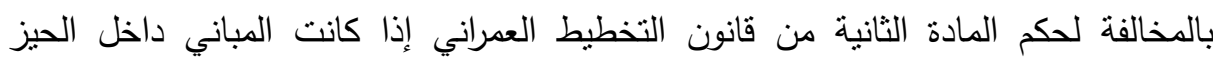

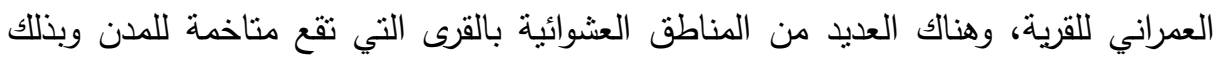

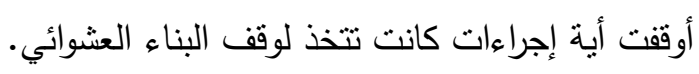

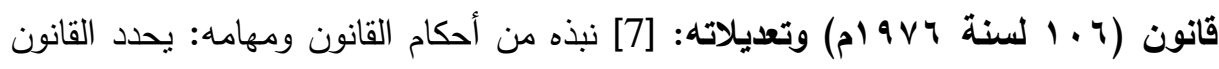

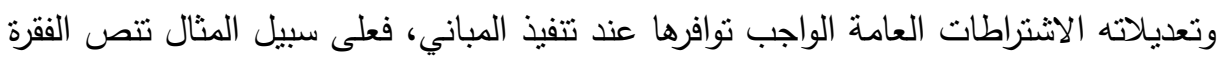

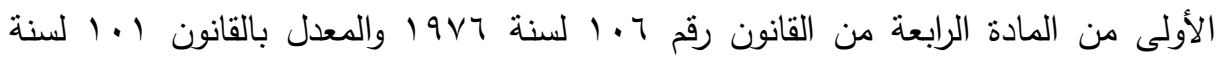

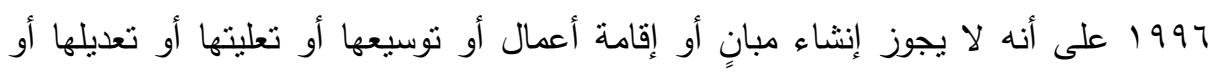

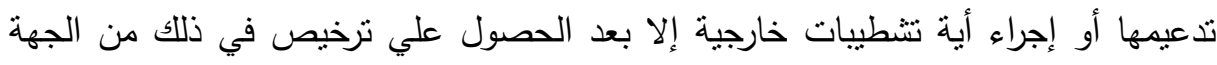
الإدارية المختصة بشئون التنظيم وفقًا لما تبينه اللائحة التنفيذية.

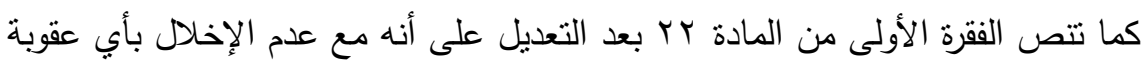

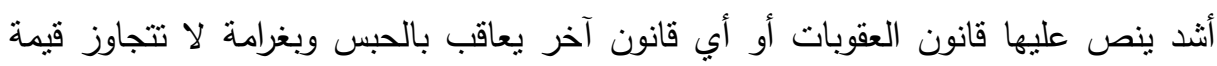

$$
\text { المجلد الثالث والأربعون، الجزء الأول، سبتمبر 11 ب r }
$$


الأعمال المخالفة أو بإحدى هاتين العقوبتين كل من يخالف أحكام المواد ع، ه من هذا

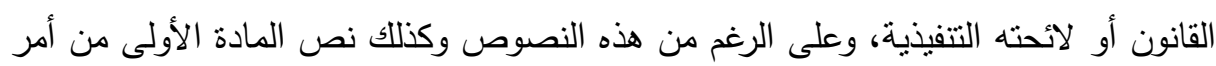

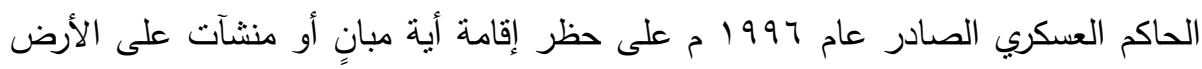

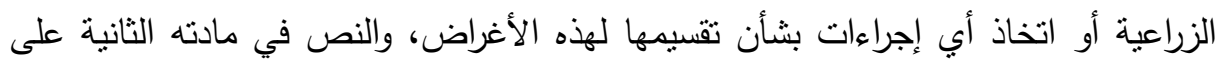

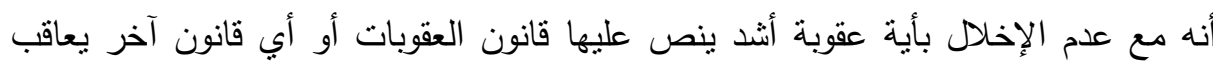
بالحبس مدة لا نقل عن سنتين ولا تجاوز خمس سنوات كل من يخالف أب حكم من أحكام

المادة السابقة.

ويناءاً على ما سبق نتج الآتى: علي الرغم من كل ذلك فقد يعتد أصحاب الثأن إلى إقامة

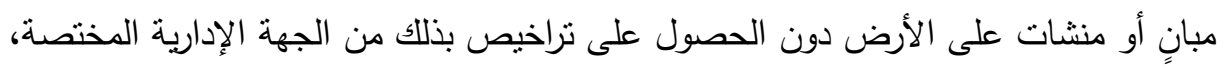

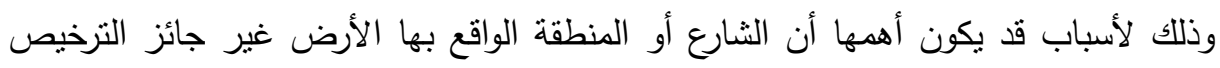

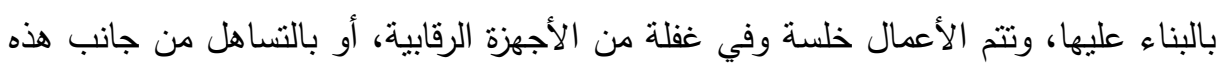
الأجهزة إما عن عمد وإما عن إهمال، ويقدم أصحاب الثنأن على البناء آملين في أحد أمرين:

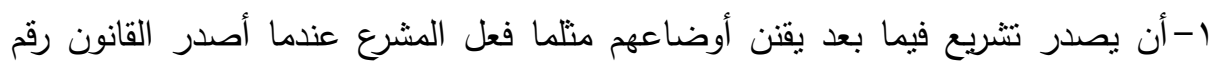

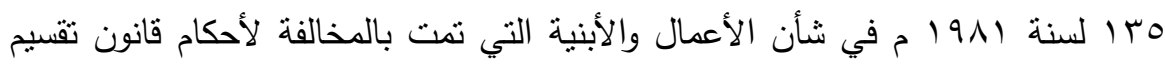

$$
\text { الأراضي. }
$$

r-إيجاد كتلة سكنية أو تجمع بشري مستقر يشكل أمرًا واقعًا بحيث لا يجوز لأجهزة الدولة

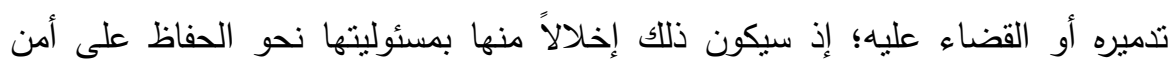

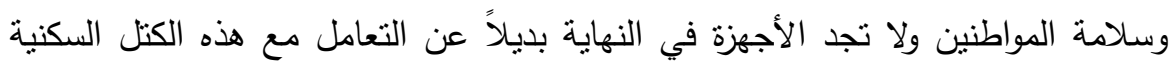

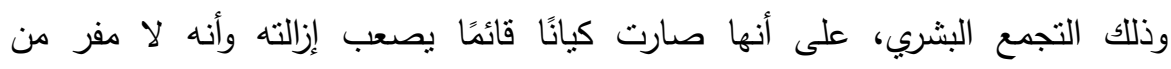

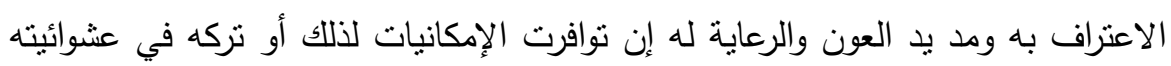
ينمو وبتزايد.

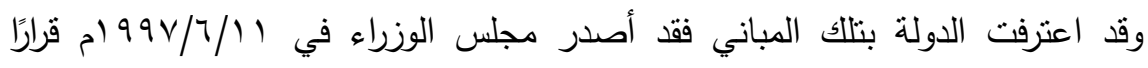
بحظر إزالة جميع مخالفات المباني التي تم انشاؤها قبل صدور أمر رئيس مجلس الوزئ لوراء ونائب الحاكم العسكري العام رقم V لسنة و997 ام، وقد استتد إلى العديد من القرارات المتعلقة

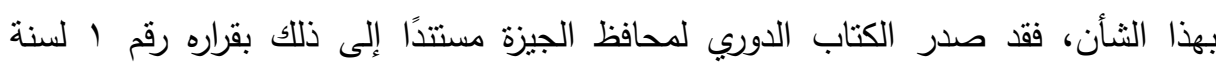

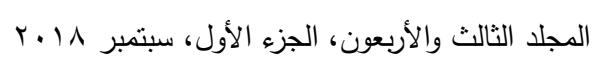


V99 19 ام بشأن القواعد التي يتعين أتباعها بصدد نتفيذ أحكام قرار مجلس الوزراء المشار إليه ومنها التجاوز عن إزالة المباني المخالفة للبناء.

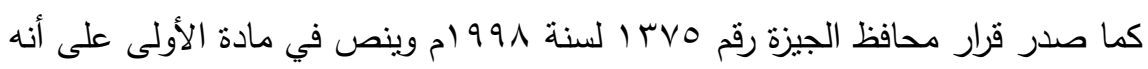
على الجهات المعنية الموافقة على طلبات المواطنين المتعلقة بتوصيل الكهرباء داخل المناطق العشوائية والمساكن الأخرى.

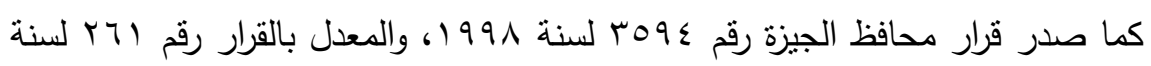

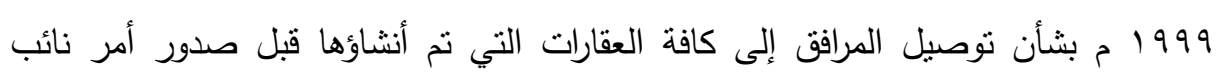
الحاكم العسكري.

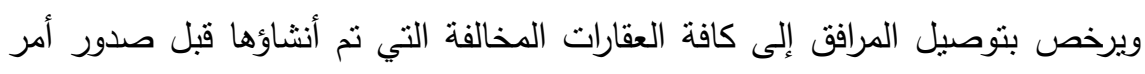

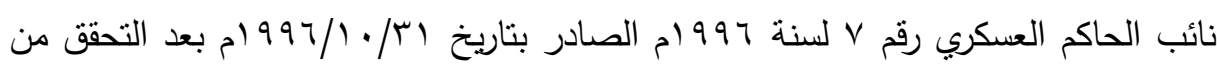

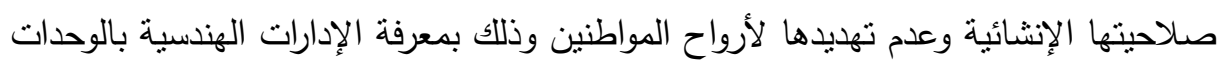
المحلية الكائن في نطاقها نلك العقارات. بالنسبة للمباني المخالفة للأمر العسكري المشار إليها وهي التي أنشئت بعد صدور أمر

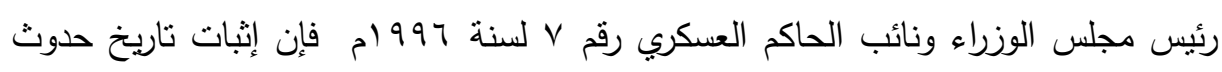
المخالفة (إقامة المبنى) يعد من الصعوبة بمكان في المناطق العشوائية حيث لا أسماء رسمية

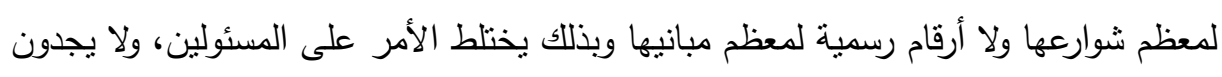

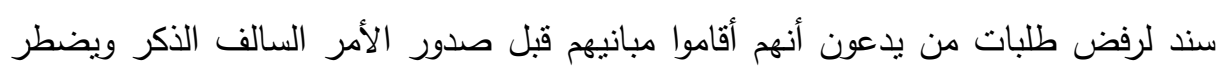
المسئولين إلى الموافقة على مد هذه المباني بالمرافق.

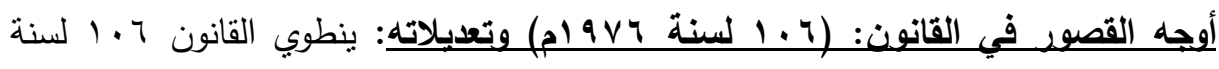
19V7 على العديد من الإجراءات الثكلية التي يستغلها المخالفون في الإنسراع بإتمام المباني

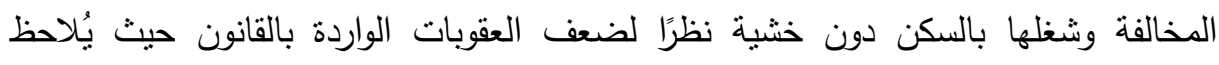
الآتي: 1-ضعف العقوبات التي سنها القانون: حيث وردت جميعها في دائرة الجنح المعاقب عليها بالحبس أو الغرامة أو كليهما (غالبًا ما يكون الحبس مع وقف التتفيذ، والغرامة لا تتتاسب

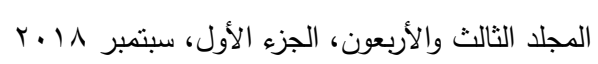




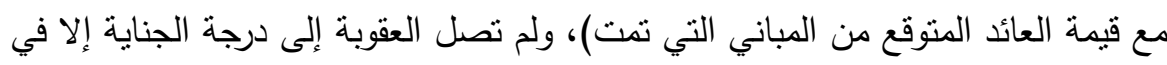

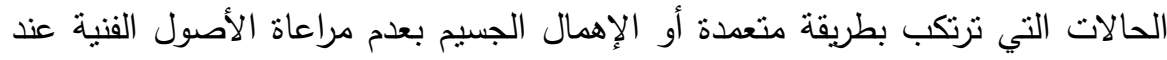
التصميم أو التتفيذ أو الغش في استخدام مواد البناء. ץ-طول الإجراءات التي سنها القانون: تتقسم الإجراءات التي سنها النهاء القانون في التعامل مع

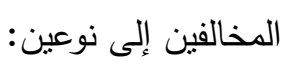
-

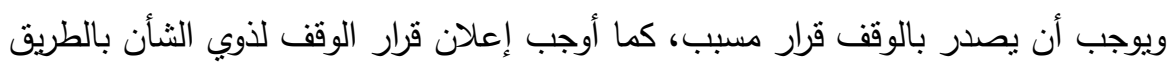

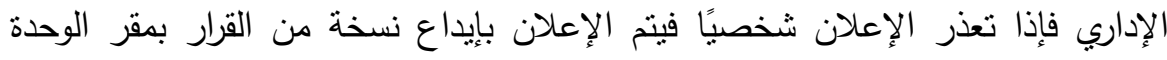

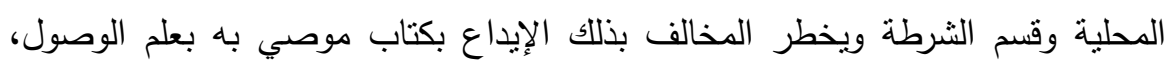

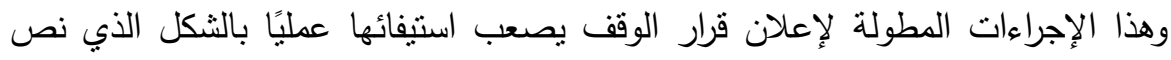

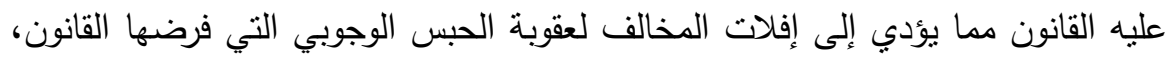

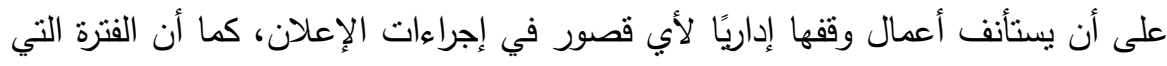

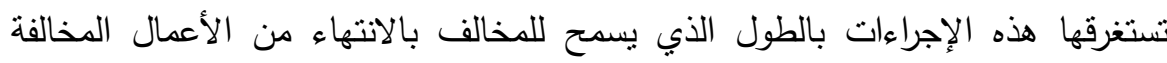
وتصبح أمرًا واقعًا خاصة لو لو أقام بالمبنى سكان.

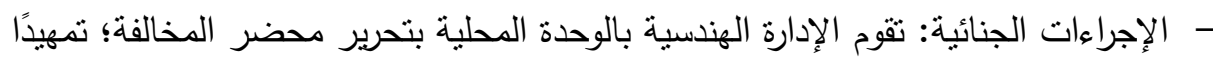

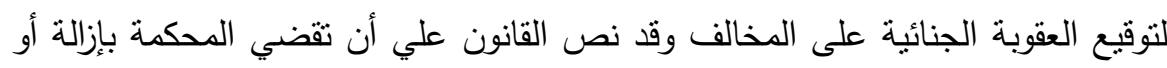

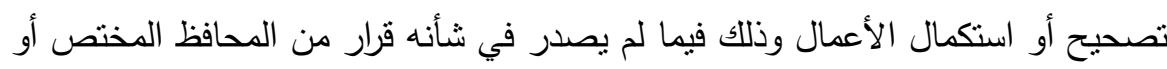

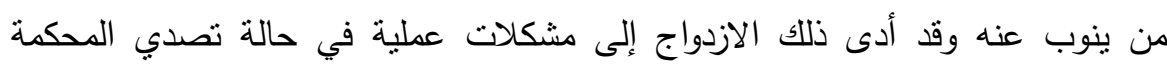

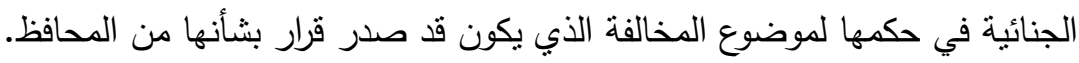

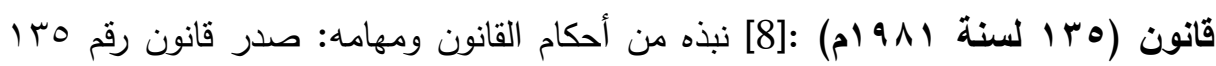

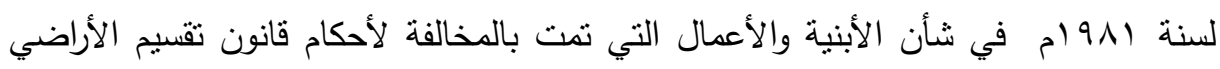

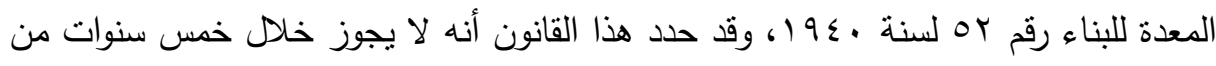

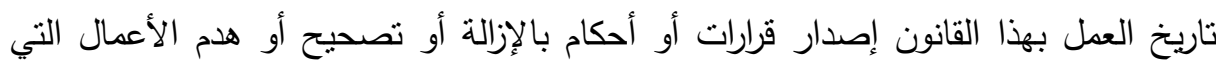

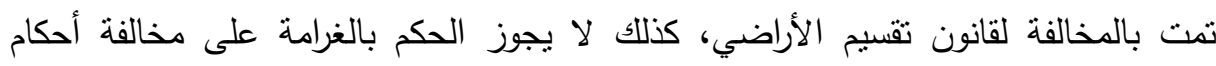




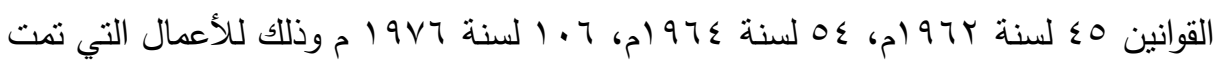

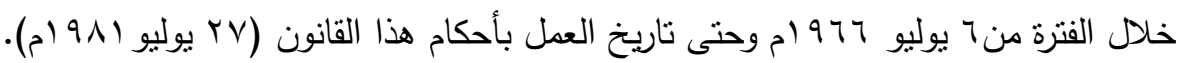
أكد القانون على أن تقوم كل محافظة بالاتفاق مع الهيئة العامة للتخطيط العمراني بإعادة تخطيط المناطق المخالفة لرفع مستواها مع إعداد مساكن جديدة لقاطني المباني التي

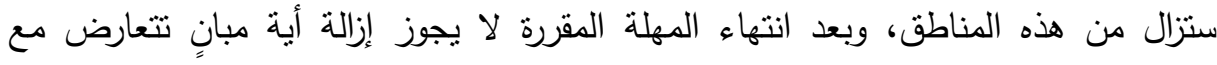

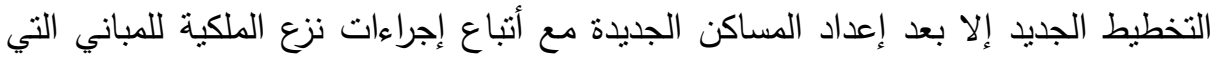

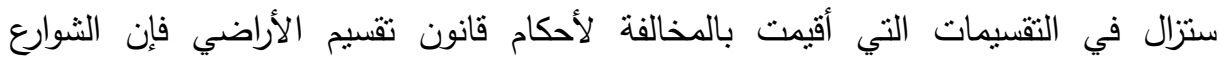
والطرقات والميادين والمتتزهات المحددة علي الطبيعة تلحق بالمنافع العامة دون مقابل، وقد

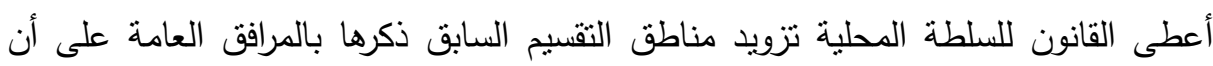
تحصل تكلفتها من الملاك بالطريق الإداري على أساس نوزيع التكاليف بنسب مسطحات

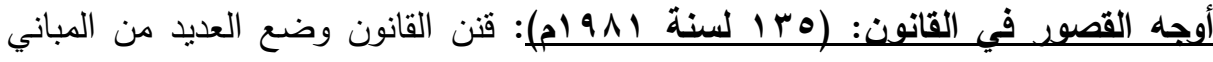
العشوائية التي أقيمت بصورة غير رسمية قبل صدور هذا القانون، كما شجع صدور هذا

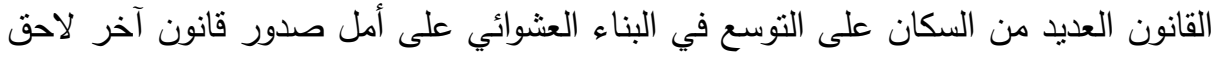
لتقنين المباني العشوائية الذي تم بعد صدور هذا القانون. المبدأ: ضرورة صدور قرار باعنماد أوضاع التقاسيم المخالفة وفقا للشروط التى بـى

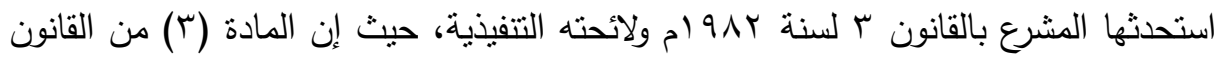

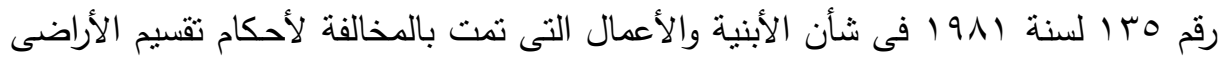

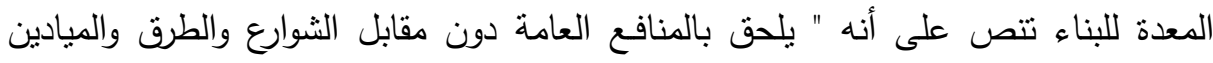

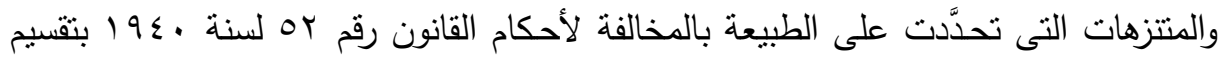

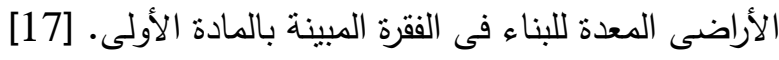

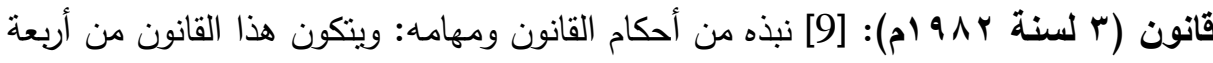
أبواب رئيسية ويحتوي على اء مادة، ويعتبر أول قانون وضع في مصر لرسم السياسة العامة

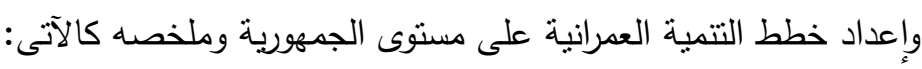

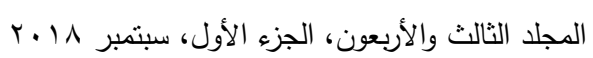


الباب الأول: في شأن تخطبط القرى والمدن ويتكون من ست مواد وتتلخص في الآتي: إعداد

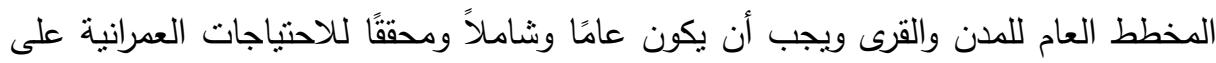

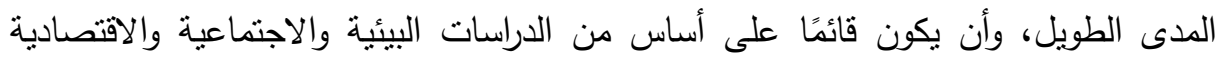

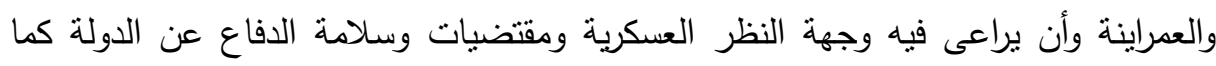

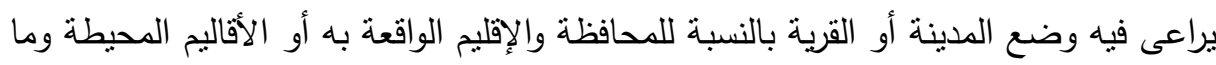
تقضي به المخططات الإقليمية المعتمدة وغير ذلك من الأوضاع التي تبينها اللائحة التتفيذية. الباب الثاني: في شأن التخطيط التفصيلي يحتوي على أربع مواد وتتلخص في الآتي: توضيح

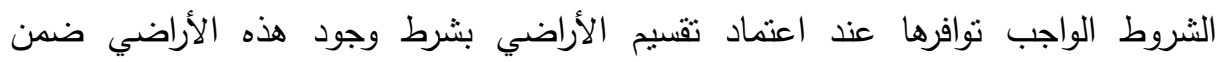

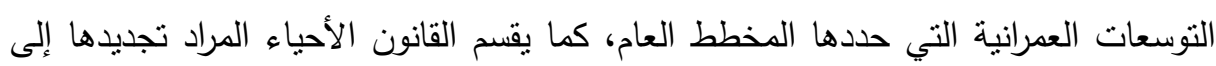
قسمين (التي تعاني من التزاحم السكاني أو المتخلفة وتقتقر إلى المرافق أو الخدمات).

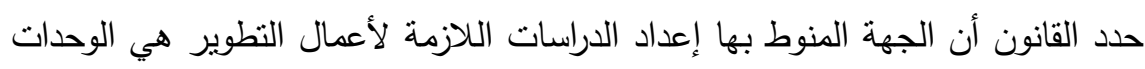

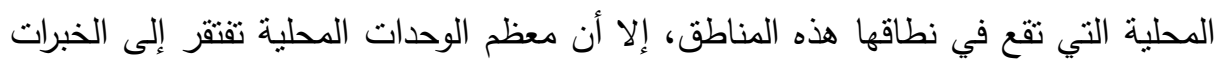

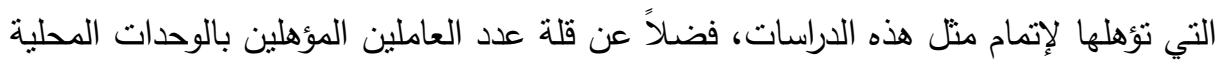

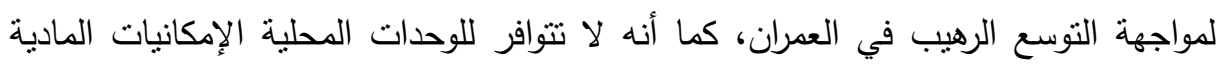
للإستعانة بالمتخصصين ذوي الخبرة فتترك تللك المناطق دون تطوير وتتفاقم مشكلاتها. الباب الثالث: في شأن تقسيم الأراضي يحتوي على خمس عثرة مادة وتتلخص في الآتي: في

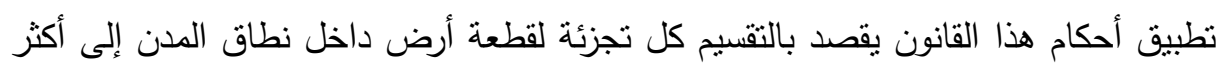

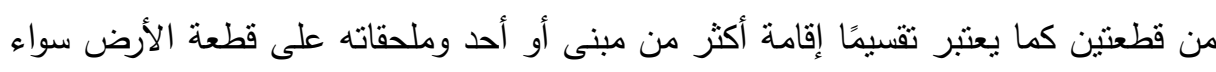

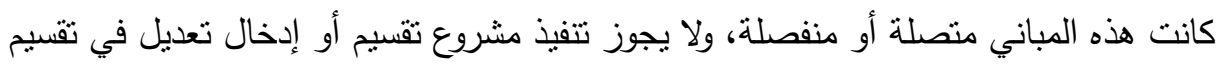

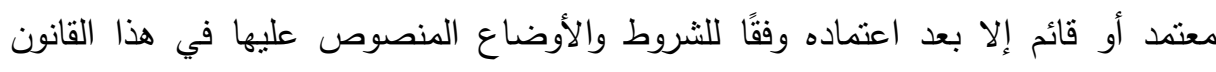
ولائحته التتفيذية. تحديد اللائحة التنفيذية لهذا القانون والمعدلات التخطيطية والقواعد والثروط والأوضاع الواجب مراعاتها في نقسيم الأراضي (نسبة المساحة اللازم تخصيصها للطرق والميادين

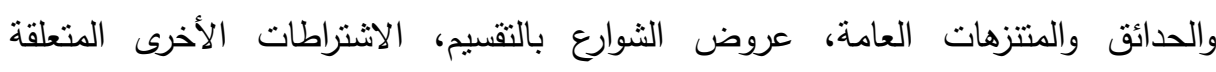
بالارتدادات وارتفاعات المباني وكثافتها السكانية والبنائية). 
الباب الرابيع: في شأن منطقة وسط المدينة ويحتوي على خمس مواد وتتلخص في الآتي:

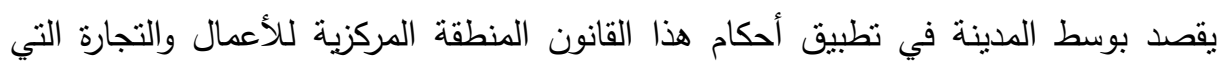
توجد بها الأنشطة التجارية والمالية وبيوت الأعمال والفنادق والمؤسسات الترفيهية والثقافية وكذا المباني الإدارية الرئيسية والصناعات الصغيرة وبعض المساكن، وتحدد الوحدة المحلية حدود هذه المنطقة في إطار التخطيط العام أو في غيابه.

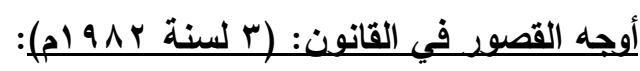
قصور الأجهزة الفنية: يمكن إرجاع التتاقض بين القوانين والتشريعات المنظمة للعمران وبين الواقع الفعلي لتطبيق هذه القوانين إلى أن القانون يعتمد علي إمكانية وسلطة الإلزام وكذلك على صلاحية الأجهزة القائمة عليه وهذا لا يتم لعدة أسباب منها:

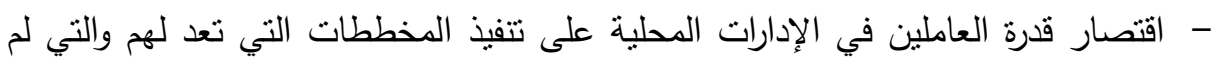

$$
\text { يشتركوا في إعدادها. }
$$

- عدم قدرة الأجهزة والإدارات المختصة على إعداد تخطبط يوائم النواحي الفنية مع لإدان الإمكانيات الفعلية للتنفيذ.

- إختصار سلطة إعداد ومراجعة المخططات في جهة واحدة لكل مدن وقرى الجمهورية

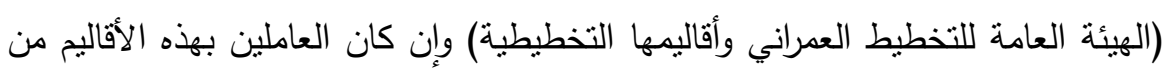
ذوي الكفاءات الفنية العالية إلا أن عددهم قليل بما لا يتتاسب وحجم العمل الضخم الموكل

$$
\text { إليهم. }
$$

- عدم وجود الإدارات القادرة على تتفيذ القانون كمًا وكيفًا. قصور الأجهزة التنفيذية: تدرجت الأجهزة الرقابية المشرفة على حركة العمران بالمدن والقرى

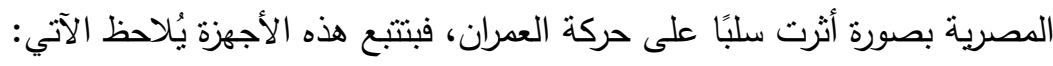

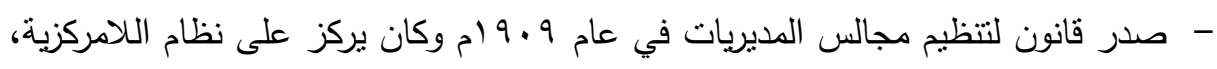
وكان من وظيفة هذه المجالس تحسين المدينة وإدارة مرافقها وخدماتها المختلفة. 
- بصدور قرار مجلس الوزراء في عام VI Vام نثأت المجالس القروية في المدن الصغيرة وبعض القرى، وتقوم هذه المجالس بإدارة مرافق المدن وأنشغال التنظيم وأعمال الطرق والبنية الأساسية والخدمات.

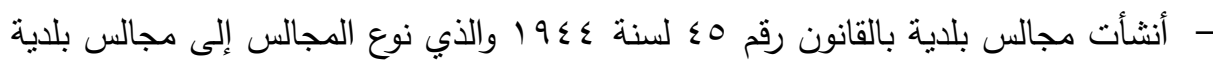
ومجالس قروية، تقوم المجالس البلدية بالإثراف على الجوانب العمرانية والخدمات الاجتماعية وتجميل المدن، أما المجالس القروية فتختص بالشئون الهندسية والعمرانية والاجتماعية والصناعية والآمن والمواصلات.

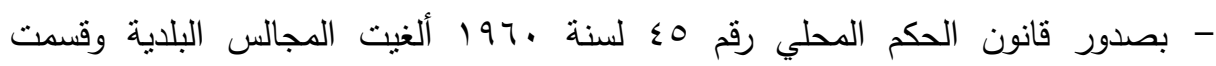
الجمهورية إلى ثلاثة مستويات : محافظات، مدن، قرى ويمنل كل منها مجلس مستقل. وبذلك أصبح مجلس المدينة يتكون من مجموعة من الإدارات المختلفة، وأصبح العمران

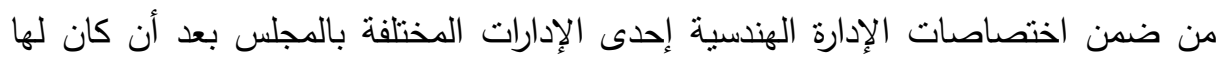

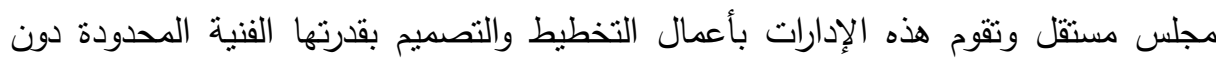
الرجوع إلى المختصين والخبراء في هذا المجال، وهكذا ضاعت شئون العمران وسط المشكلات

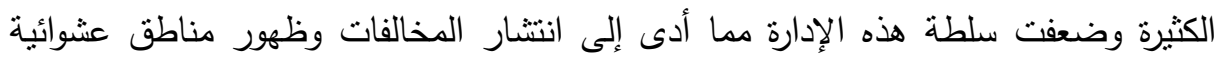

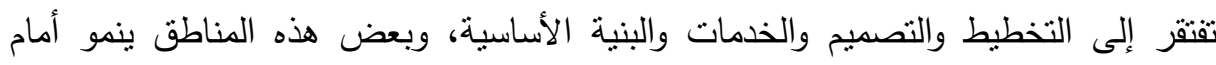
أعين القائمين على الإدارات الهندسية دون أن يكون لديهم القدرة على إيقافها.

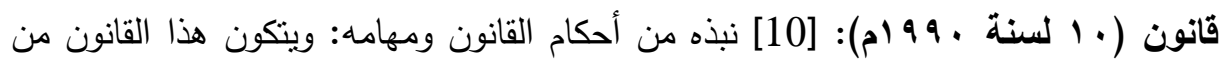
خمسة أبواب ويحتوي على تسع وعشرين مادة بشأن نزع ملكية العقارات للمنفعة العامة.

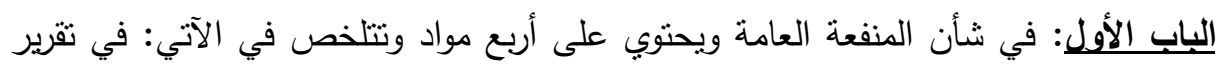

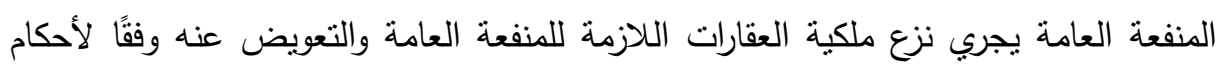

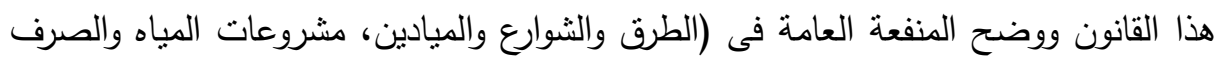

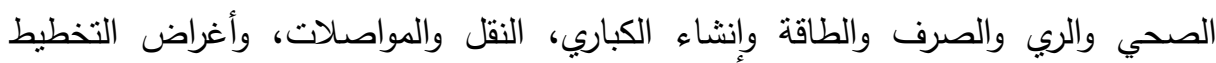
العمراني وتحسين المرافق العامة). ويكون تقرير المنفعة العامة بقرار من رئيس الجمهورية، مرفقا به مذكرة بييان المشروع تهرئ المطلوب تتفيذه، ورسم بالتخطيط الإجمالي وللعقارات اللازمة له. له. 
الباب الثاني: في شأن الفصل في المعارضات والطعون ويحتوي على ثلاث مواد وتتلخص في أن يكون حصر وتحديد العقارات والمنشآت التي تقرر لزومها للمنفعة بواسطة لجنة مؤلفة من فن فئن مندوب الجهة القائمة بإجراءات نزع الملكية ومن أحد رجال الإدارة المحلية، ويتم تقدير

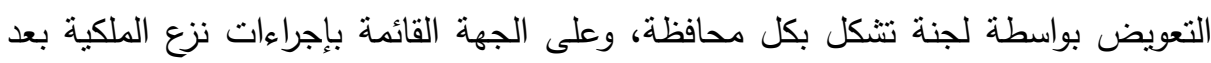

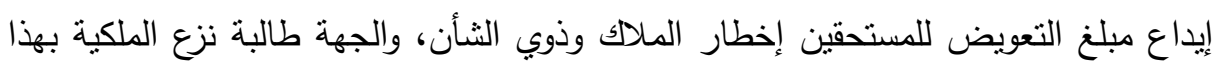

$$
\text { العرض بكتاب موصى باه مصحوب بعلم الوصول. }
$$

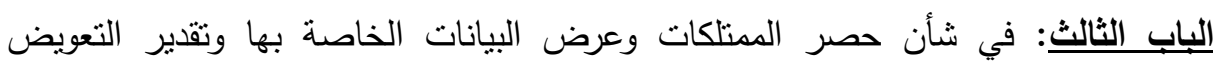

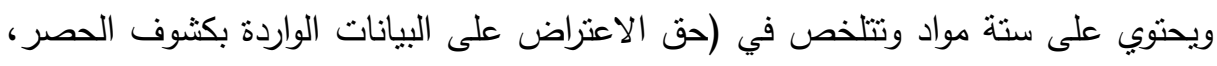

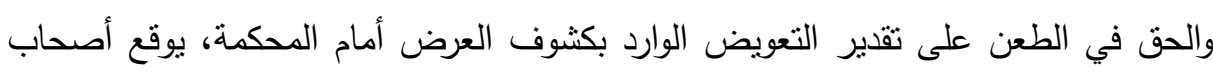

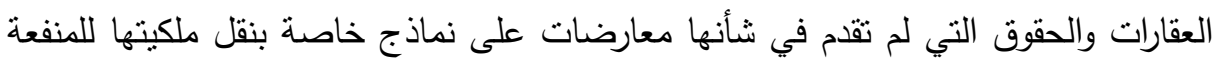

الباب الرابع: في شأن الاسنيلاء المؤقت على العقارات ويحتوي على ستة مواد وتتلخص في

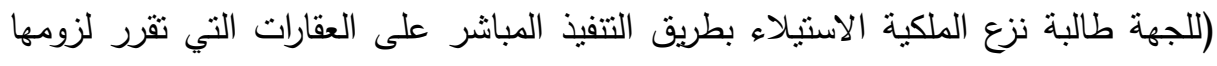
للمنفعة العامة، بكتاب موصى به مصحوب بعلم الوصول، الإجراءات الخاصة بتقدير قيمة

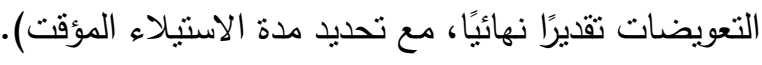

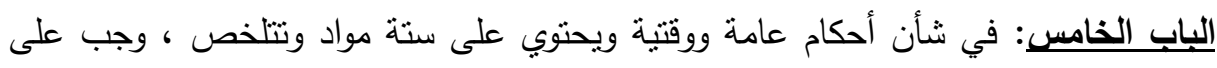

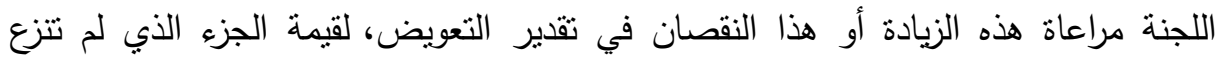

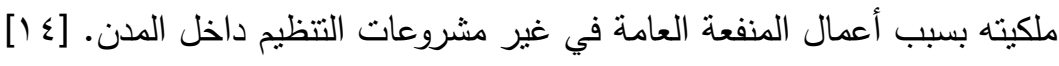

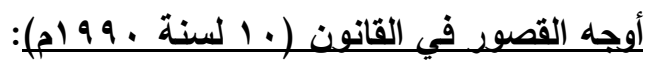
- عدم توفير العلم الحقيقى والفعلى للملاك الحقيقيين للعقارات محل نزع الملكية بإجراءات نزع الملكية المتعلقة بعقاراتهم حفاظا على حقوفهم. - عدم إعطاء مستحق التعويض تعويضا عادلا، ويتم على سبيل المثال بإضافة نسبة من

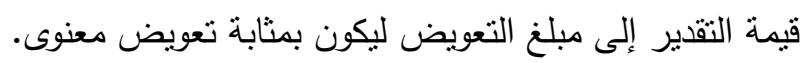


- إيداع مبلغ التعويض فى حساب بنكى يدر عائدا يستفيد به مستحق التعويض فى حالة ما إذا تأخر صرف التعويض.

- عدم إعطاء المحافظ حق إصدار قرارات الاستيلاء المؤقت لبعض العقارات لحالات

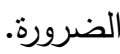

- لابد من إلغاء المادة • ب بالقانون الحالى لتفادى التأخير فى إجراءات صرف التعويضات تماثيا مع أحكام الدستور التى أوجبت دفع التعويض مقدما مع الاحتفاظ بحق الجهة

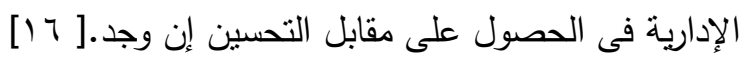

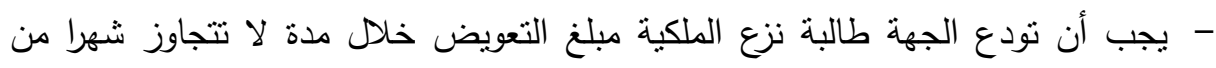
تاريخ صدور القرار ، وذلك لطول المدة.

- لابد على الجهة القائمة بإجراءات نزع الملكية بإجراء الحصر الدقيق وعمل قائمة بالعقارات

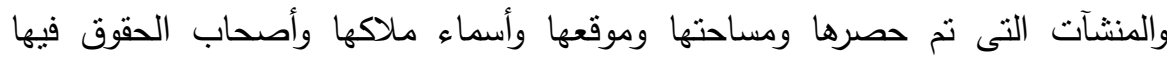
ومحال إقامتهم والتعويضات المقدرة.

قانون (9 11 السنة ^ . . ץ م): نبذه من أحكام القانون ومهامه: وهو القانون الذي تم بموجبه

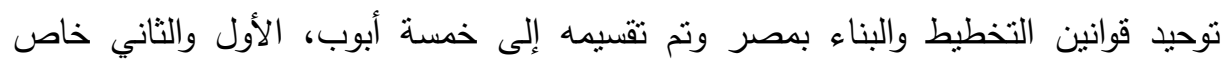

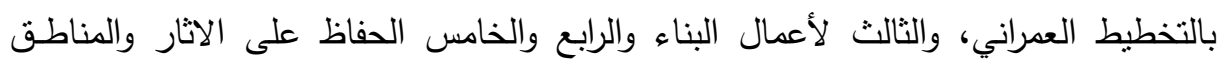

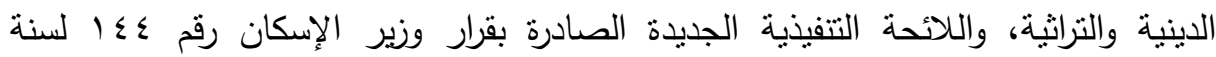
. الباب الأول: التخطيط العمراني الفصل الخامس مناطق إعادة التخطيط والمناطق غير المخططة. [15] - مادة (ع 7): تحدد مناطق إعادة التخطيط الني ينطبق عليها الحالات المنصوص عليها في القانون والتي يقرها المجلس بناءً على عرض المحافظ المختص كمناطق تخضع لتعديل

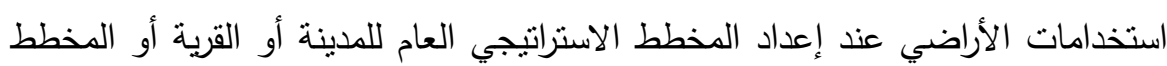

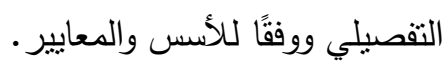
- مادة (70): الإجراءات الخاصة بإعداد واعتماد المخطط التفيلي لمنطقة إعادة التخطيط. ويتبع ذلك من إعداد واعتماد المخططات التفصيلية للمناطق الواردة بالمخطط 
الاستراتيجي العام للمدينة أو القرية أو المخطط التقصيلي لمناطق إعادة التخطيط

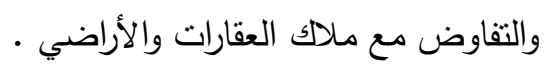

- مادة (77): خطوات وإجراءات التفاوض مع ملاك العقارات والأراضي داخل منطقة تعديل الاستخدام وإعادة التخطيط. - مادة (TV): لجنة الحصر والتفاوض: يقوم المحافظ بتشكيل لجنة لحصر والتقاوض مع الملاك في منطقة إعادة التخطيط للمدينة أو القرية. - مادة (؟^): مهام لجنة الحصر والتفاوض بالمهام الآتية (حصر العقارات داخل منطقة الشروع وأسماء الثاغلين والملاك، والمستتدات الملكية والثاغلين والتفاوض المبدئي - مادة (79): لجنة التقيبيم: من خلال مقيم أو أكثر أو لجنة (حسب الأحوال) للقيام بالأعمال (معاينة موقع المشروع ، وعمل خرائط التثمين، وتقدير إجمالي التعويض للملاكى).

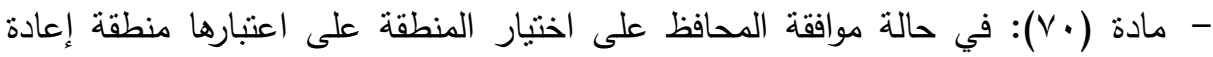
تخطيط ذات أولوية في التعامل وإقرارها من المجلس، يتم تكليف اللجنة بالتفاوض.

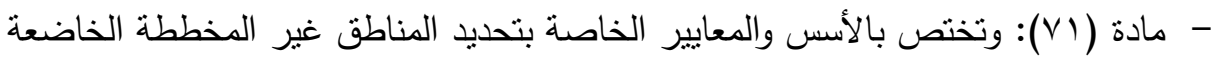

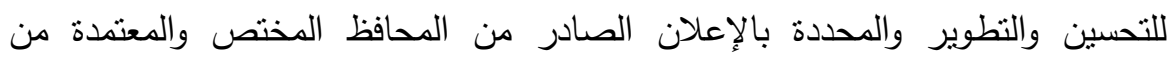
المجلس، وهي ذات الأسس والمعايير الخاصة بتحديد مناطق إعادة التخطيط المشار إليها

\section{ايجيبيات قانون البناء الجديد: [12]}

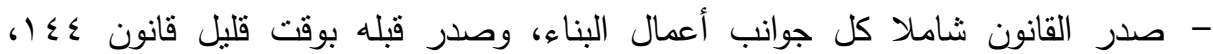
الخاص بهدم المبانى غير الآيلة للسقوط، والحفاظ على الثروة العقارية، والذى يشمل جميع نواحى التخطيط العمرانى والتتسيق الحضارى. - أهم الجوانب التى عالجها القانون عدم قيام أى مبنى دون ترخيص، ولن يصدر الترخيص إلا بناءً على تخطبط علمى. 
- تيسير إجراءات استخراج التراخيص ووضع مسؤولية ذلك على عاتق المهنس المختص بالإشراف على البناء، وجعل صدور كل الاشتراطات البنائية تتجمع فى جهة بنائية واحدة، بحيث يكون 》الحى" هو الجهة الوحيدة لإصدار شهادة صلاحية البناء.

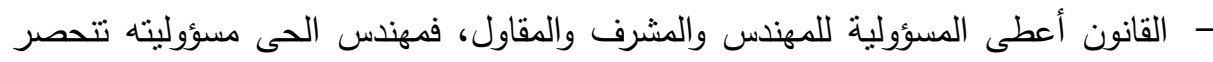
فقط فى التأكد من أن الاشتراطات مطبقة، فالمسؤولية الفنية تقع على عاتق المهندس،

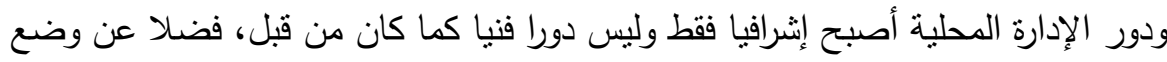
حد أقصى للرسوم التى يدفعها طالب الترخيص، والتى نم تحديدها بألف جنيه فقط بزيادة التداد r\% سنويا، وهناك محافظون أصدروا قيمة أقل من هذا وذلك ادى الى تقليل الفساد. - استحدث القانون احكاما تقضي بالسماح بالبناء علي العقارات المقامة بدون نرخيص في

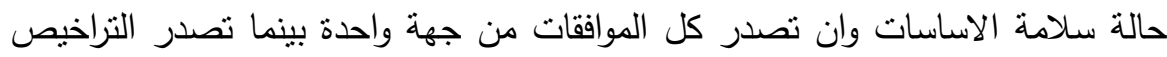

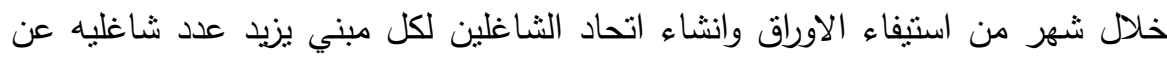
خمسة يكون له حق مطالبة اعضائه بسداد تكاليف الصيانة التي تقرها الجمعية العمومية.

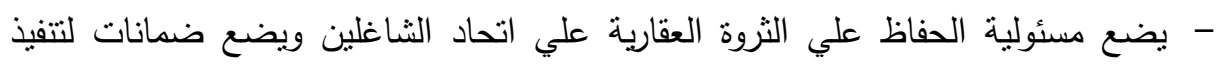
الأعمال طبقا للمواصفات القباسية والترخيص. - وجود مركز إقليمى للتخطيط والتتمية العمرانية بكل اقليم اقتصادى يتبع الهيئة العامة

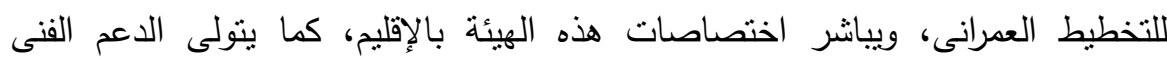

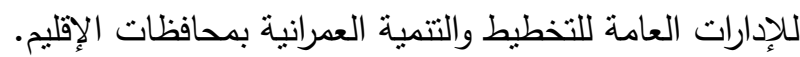

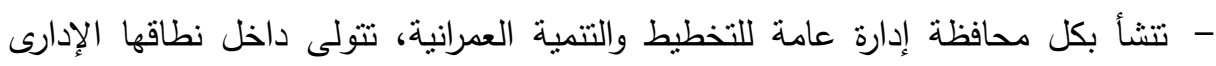

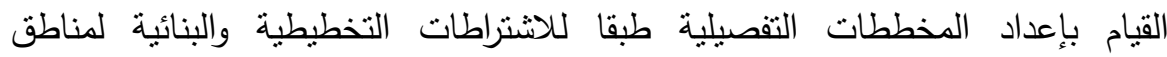
استعمالات الاراضى المختلفة وبرامج وأولويات مشروعات التتمية المتكاملة بالمخطط الاستراتيجى العام المعتمد للمدينة أو القرية.

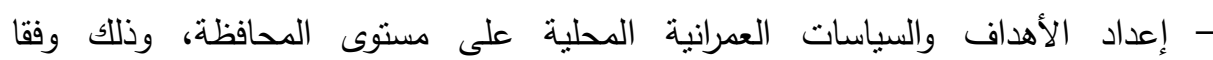
للاحتباجات التى يحددها المجلس الثُبى المحلى للمحافظة. - مشاركة الوحدة المحلية المختصة والمجالس الثعبية المحلية والأجهزة النتفيذية المختصة وممتلى المجتمع المدنى والأهلى. 
- عرض الإدارة العامة للتخطيط والتتمية العمرانية داخل الوحدة المحلية مشروع المخطط الاستراتيجى العام، وتتلقى ملاحظات المواطنين والجهات ذات الصلة والمجلس الثُعبى المحلى.

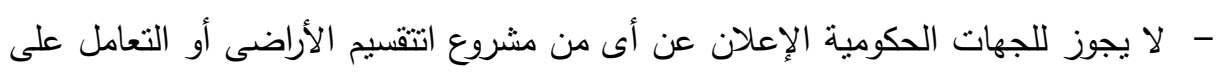

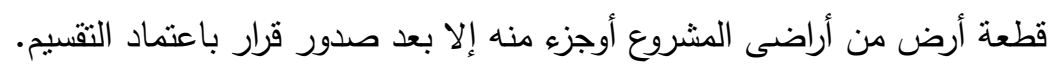
نزال بالطريق الإدارى على نفقة الماللك المخالفات الآتية: - المبانى والمنشآت والأعمال التى تقام بدون ترخيص. - الأعمال المخالفة لقيود الارتفاع المقررة قانونا والصادر بها قرار المجلس الأعلى للتخطيط والتتمية العمرانية.والتعديات على خطوط التتظيم ومناطق الردود المقررة بالاثتراطات.

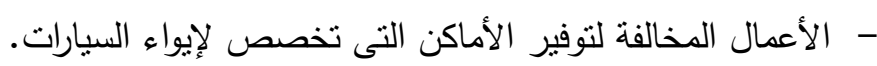
- التعديات على الأراضى الخاضعة لقانون حماية الآثار . - المبانى والمنشآت والأعمال التى ثقام خارج الحيز العمرانى المعتمد للمدينة أو القرية.

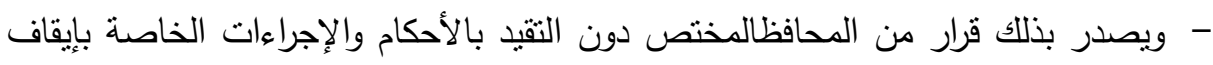
الأعمال ولا يجوز التجاوز عن إزالة هذه المخالفات. سليبات قانون البناءع الجديد:

- مهندسوا الأحياء والمدن بالإدارة الهندية مازالوا يتعاملون مع القانون الجديد بنفس منطق

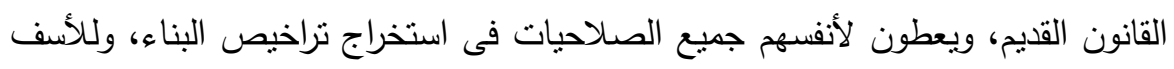

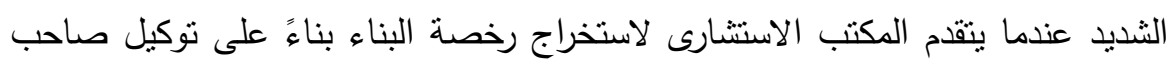

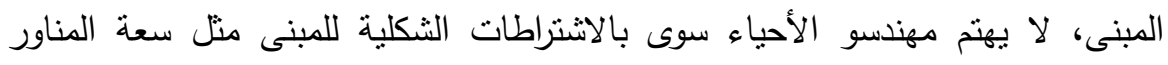
والردود والارتفاعات فقط، ولم يستوعبوا أن المكتب الاستشارى أصبح المسئول الأول

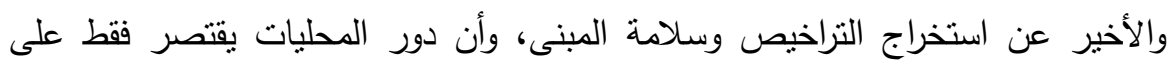
مراجعة الأوراق والتأكد من صحتها. [3ن 
- اغفال اللائحة لمشروعات المنفعة العامة كبناء المقابر ومحطات المياه ومحطات الكهرباء وأماكن تدوير القمامة ومحطات البنزين والغاز والتى يسنلزم نقلها خارج الكتلة السكنية

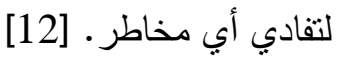

- اللأحمة إهتمت فى الأساس بالتخطبط العمرانى والتتسيق الجمالى، وأغفلت المشاكل

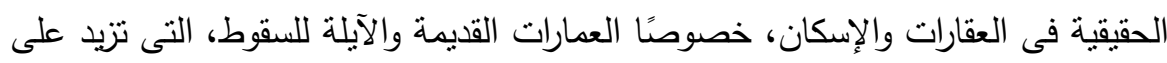

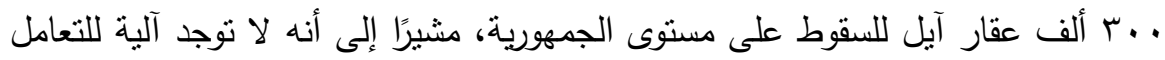
مع هذا الملف الخطير الذى يهدد أرواح آلاف المواطنين، وان القانون تضمن إنثاء صندوق لترميم المساكن القديمة، إلا أنه لم يصدر شىء فى الحى اللائحة التنفيذية بهذا الخصوص. - ويتضح أن الإفراط في التعديل والإلغاء والإعفاء في القوانين واللوائح والتشريعات على في فترات زمنية قصيرة يؤدي الى إضعاف فاعلية القيود التنظيمية، موضح بالثكل رقم (r)

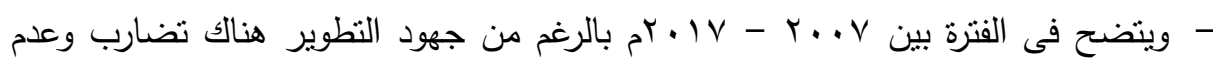
وجود خطة شاملة لتطوير المناطق العشوائية. [12] - غياب مبدأ الفصل بين السلطات العامة التشريعية والتنفيذية والقضائية: يعد من أهم تداعيات غياب قانون التخطيط العمراني والآثار المترتبة عليه، وقد تبين ذلك من منابعة وتحليل واقع عملية التخطيط العمرانى يتبين غياب مبدأ الفصل بين السلطات العامة النتريعية والتتفيذية والقضائية، كأحد أهم المبادئ الدستورية والقانونية التي تحكم عمل بلتين السلطات العامة للدولة، وتحقق النوازن فيما بينه. [3] ـ ل 
مجلة العلوم البيئية

معهد الدراسات والبحوث البيئية - جامعة عين شمس لهس

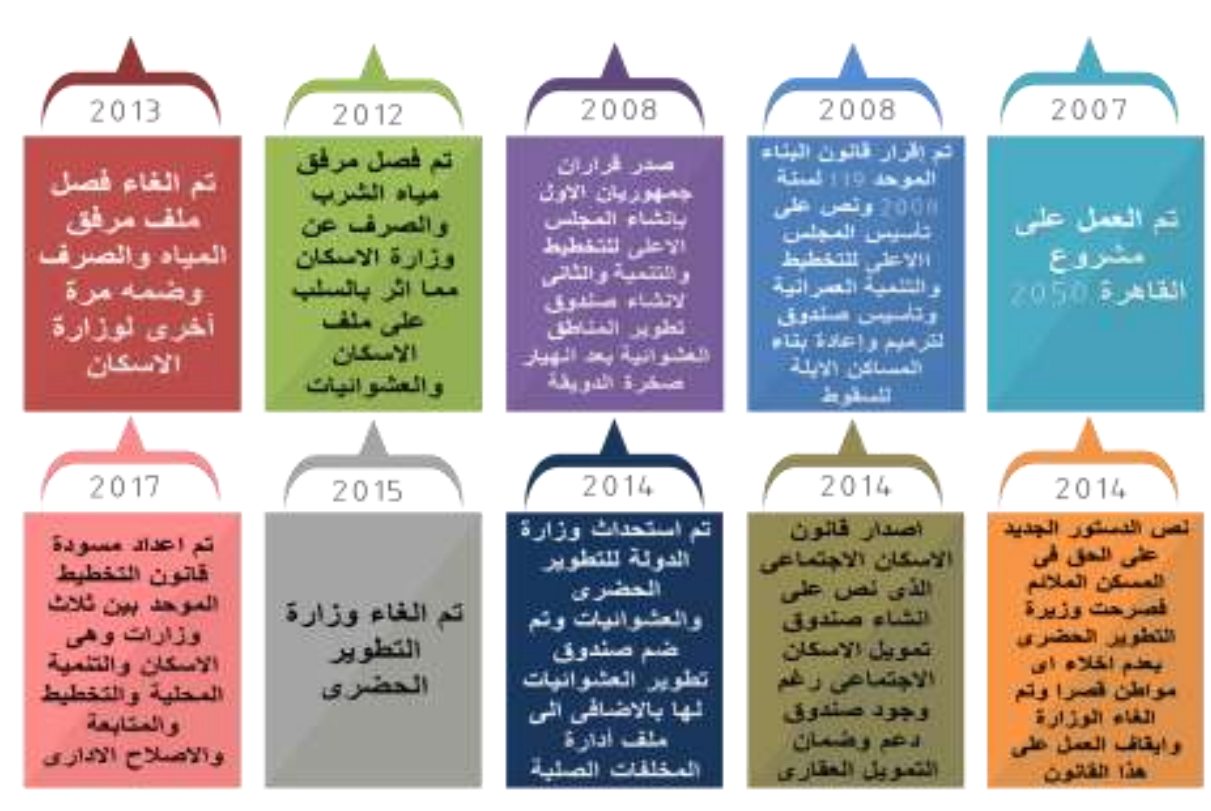

$$
\text { المصدر: من إعداد الباحث }
$$

شكل(ץ): القوانين والتشريعات المنظمة للعمران على فترات زمنية قصيرة

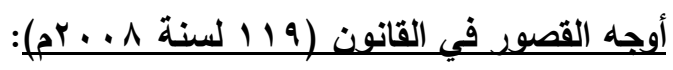

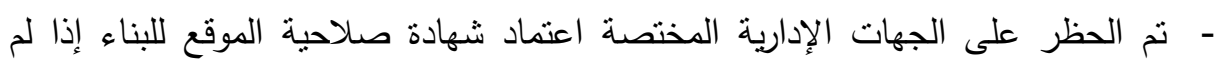

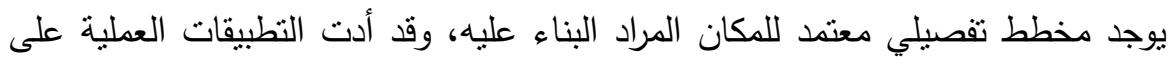

$$
\text { هذا النحو إلى مزيد من التخبط والارتجال. }
$$

- ظهر القصور القانوني، حيث ألزم الجهات الإدارية المختصة بإعداد المخطط العمراني العام كل خمس سنوات، وفي حالة عدم وجوده فقد أوجب عليها إعداد مخطط عمراني مؤقت في خلال شهرين من تاريخ صدور اللائحة الخاصة بهذا القانون، ولم تمنتل

$$
\text { الجهات الإدارية المختصة بوضع هذه المخططات المؤقتة. }
$$

- - خلو القانون من وجود نص لمجازاة ذلك الإخلال المنسوب لتلك الجهات، فضلاً عن خلوه

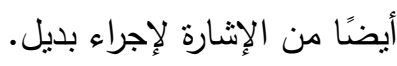


الملخص: تتاول هذا البحث القوانين والتشريعات المنظمة للعمران من حيث تعريف تشريعات العمران، وشكل العلاقة بين الأطراف المرتبطة بالتخطبط، وأول القوانين التى نتظم العمران

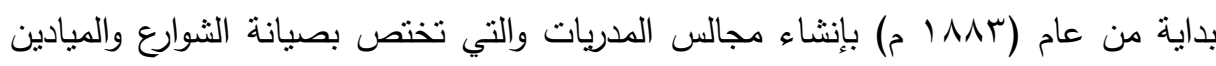

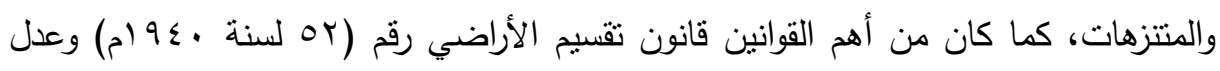

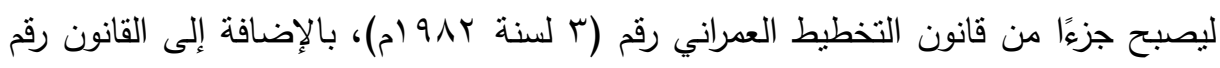

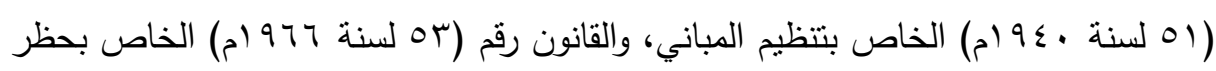

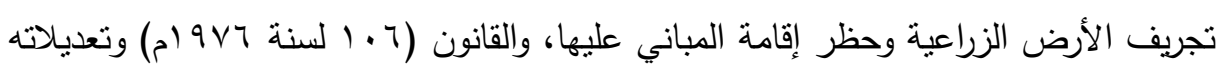

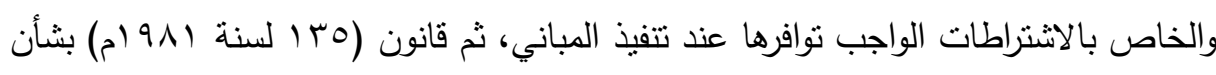

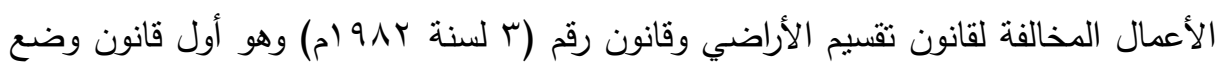

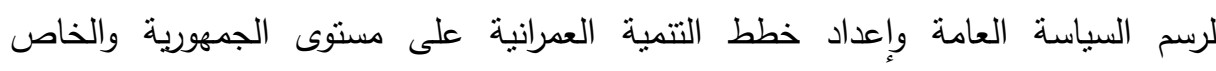

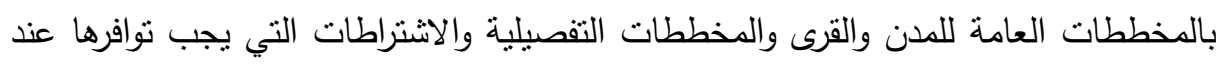
تقسيم الأرض وتحديد الجهة المنوط بها إعداد الدراسات اللازمة لأعمال التطوير .

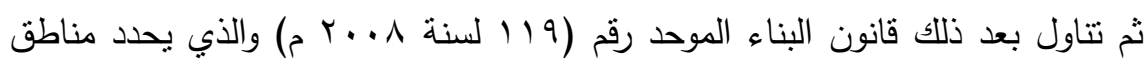
إعادة التخطيط كمناطق تخضع لتعديل استخدامات الأراضي عند إعداد المخطط الاستراتيجي

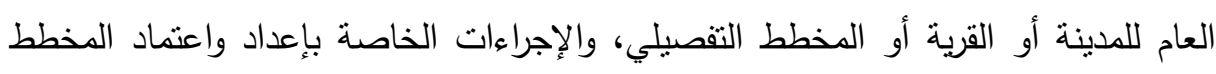

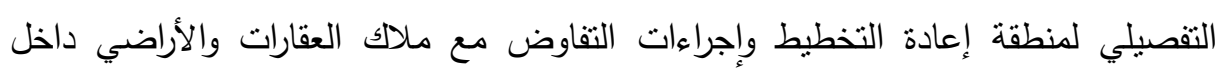

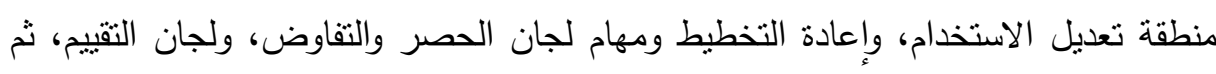

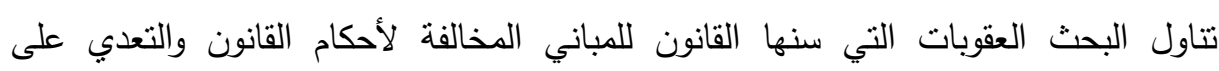
الأراضي الزراعية وقصور الأجهزة التنفيذية والرقابية المشرفة على حركة العمران. 
مجلة العلوم البيئية

معهد الدراسات والبحوث البيئية - جامعة عين شمس

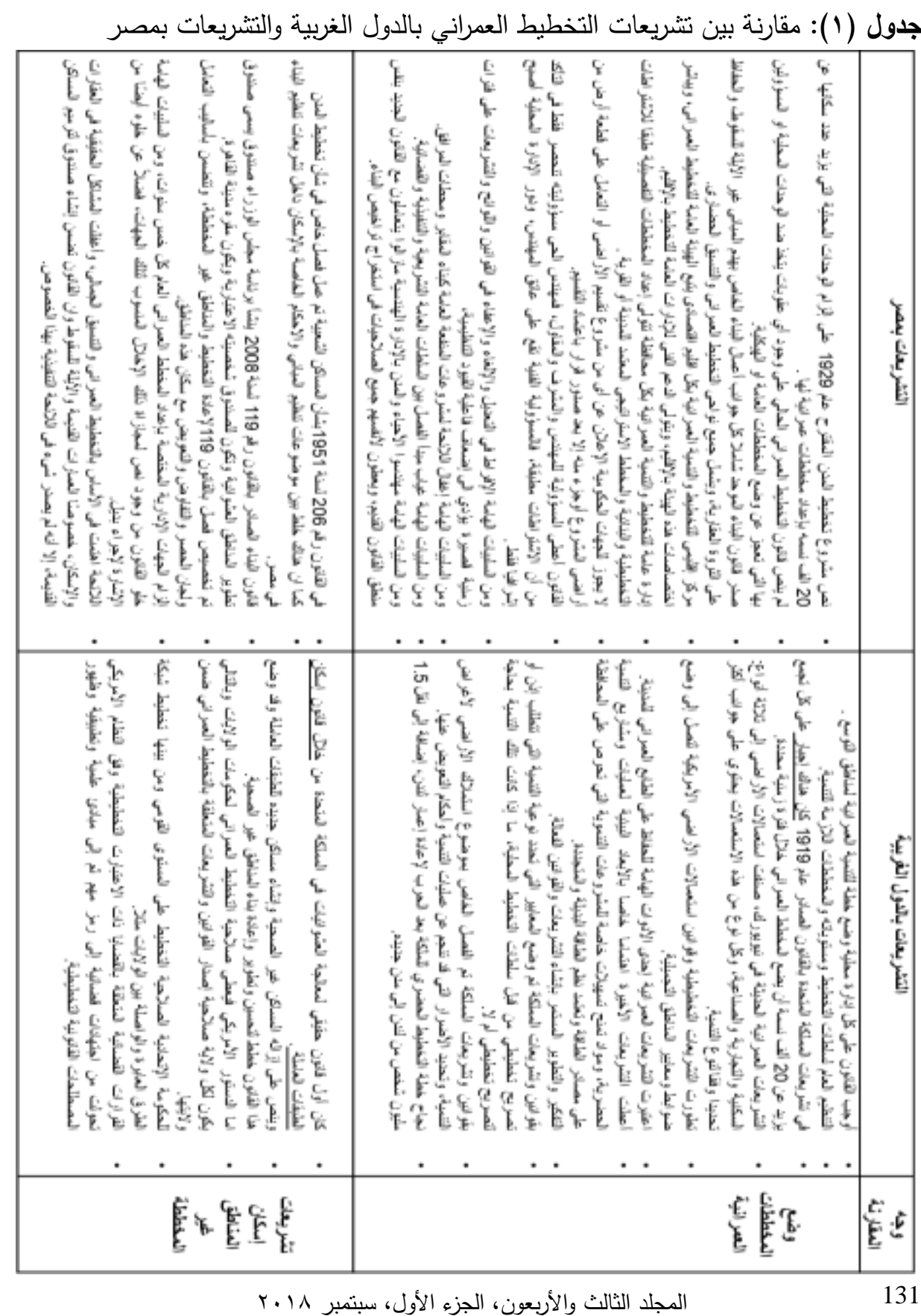




\section{المثأئ}

قد نم استعراض القوانين والتشريعات الخاصة بالتخطيط العمرانى مع إلقاء الضوء على قانون البناء الموحد (الجزء الخاص بالمناطق غير المخططة) مع أستعراض انظمة القوانين الخاصة بتلك المناطق فى الدول الغربية ومن ثم بمكن الخروج بالنتائج الآتية:

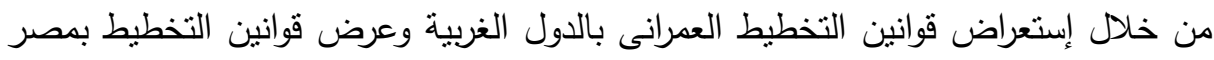
بمكن الخروج بعدة ملاحظات وهى: ( ) وجود قصور بالتشريعات العمرانية. r) نتشرك معظم التشريعات العمرانية ان لم تكن كلها في مجموعة من العوامل أدت الى الحد

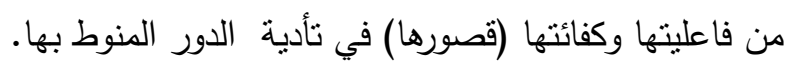

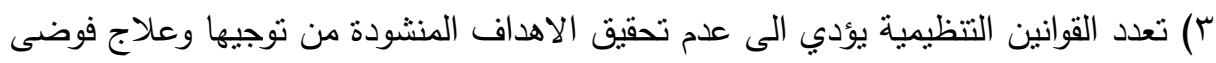
البناء. ء) الإفراط في التعديل والإلغاء والإعفاء في القوانين واللائح والتنشريعات على فترات زمنية قصيرة يؤدي الى أضعاف فاعلية القيود التنظيمية. 0) تعرض القانون الواحد لأكثر من موضوع وذلك قد يسبب مشكلة لدى مستخدمي التشريعات إذ لايوحى إسم النتريع بمضمونه في أغلب القوانين. T) أقتباس نتريعات التخطيط والبناء من نماذج لادارة النمو العمراني في الدول الغربية لاتتلائم مع الظروف السائدة ولا مع البيئة العربية وعدم الاعتماد الكلي على الكفائات

$$
\text { المتواجدة بالدولة. }
$$

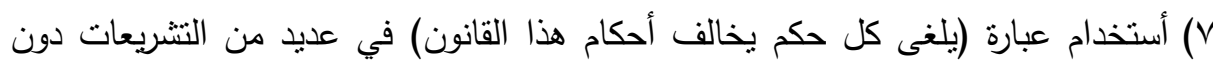
تحديد لهذة الاحكام سبب صعوبة في معرفة مدى سريان أو الغاء التشريعات السابقة. ^) تداخل بعض المواد بالقوانين مع عدد من القوانين الاخرى في موادها.

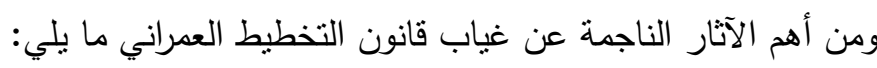

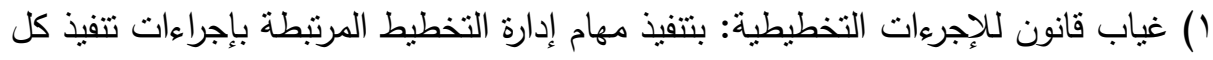
عملية تخطيطية من الناحية الزمنية والمستتدات المطلوبة. 
r) ضعف فاعلية التشريعات والقوانين القائمة: فالتخطيط العمراني لا بعتبر أداة تغيير

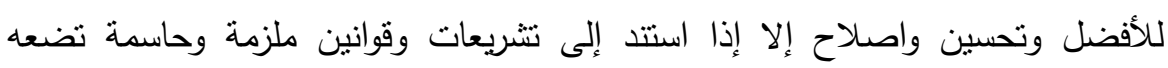

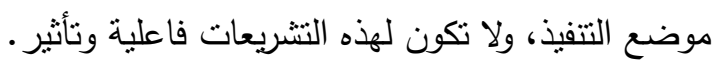

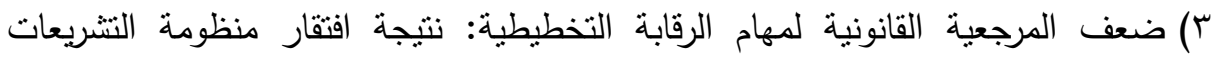
التخطيطية القائمة للنصوص القانونية التي تشكل الاطار القانوني الذي ينظم ويضبط

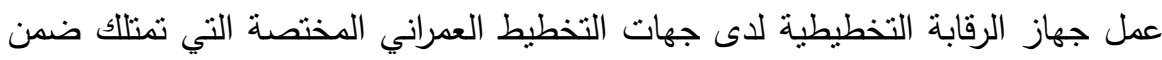
كوادرها مثل هذا الجهاز، ويعتبر هذا الأمر أيضا من أسباب ضعف لته فابه فاعلية التشريعات

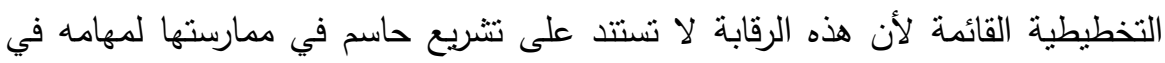

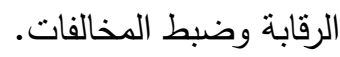

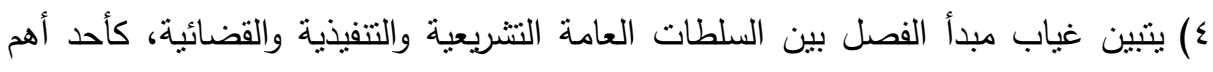
المبادئ الدستورية والقانونية التي تحكم عمل السلطات العامة في الدولة، وتحقق التوازن فيما بينها، حيث تمارس الجهات المختصة بالتخطبط العمراني، كافة السلطات العامة التشريعية والتتفيذية والقضائية مجتمعة بطرف واحد، ويغيب عن عملها الالتزام بمبدأ الفصل بين السلطات، ومن هذه الممارسات على سبيل المثال: - عدم التقيد والالتزام التام، بما تصدره تلك الجهات من أنظمة ومعايير فنية، فهي السلطة المشرعة وهي السلطة المنفذة، وبالتالي تستطيع تغييب النص في أب وقت لا تريد ان تلزم نفسها فيه. - غياب الآلية الخاصة بمراجعة قرارتها والطعن فيها لغياب النصوص النتريعية اللازمة لذلك.

0) ضعف التشريعات العمرانية على مستوى التخطيط الاستراتيجي العام: أصبحت مخططات

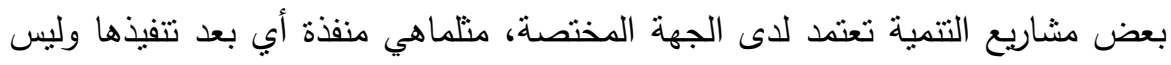

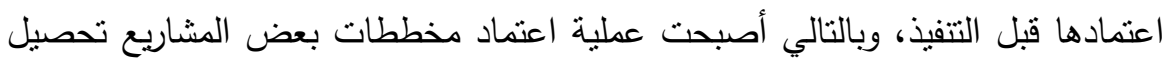
حاصل كما يقال، فأصبحت عموما المخططات ترجمة لما هو منفذ وليس كما هو مخطط 
وصارت لاحقة وتابعة لما هو منفذ وليست سابقة وموجهة لما سوف يعتمد، لما له من

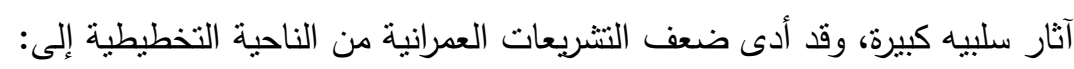
- غياب الموجه الأساسي للتخطيط الاستراتيجي وخطط وبرامج النتمية الحضرية والالتزام بمبادئ التتمية المستدامة.

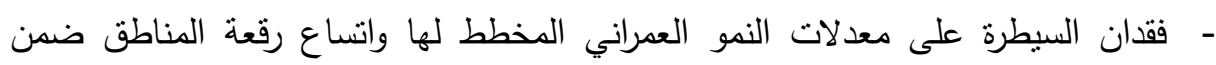
المنطقة الحضرية وزيادة المعدلات السكانية، بما يتناقض مع خطط وبرامج التنمية وموجهات تتفيذ المخطط. 7) كما أن هناك نتيجة طبيعية ألا وهي: عدم وجود مراجعة دورية للتشريعات القائمة واقتراح

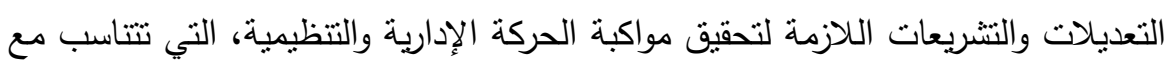
سرعة التتمية الحضرية والعمرانية. V) عدم إمكانية تلافي النقص أو تصحيح الخطأ في الوقت المناسب، ويرجع ذلك إلى أسباب

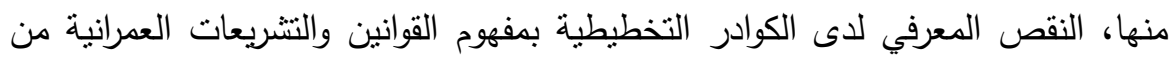
الناحية القانونية البحتة، والافتقار إلى الكوادر المؤهلة لاقتراح وتطوير التشريعات العمرانية

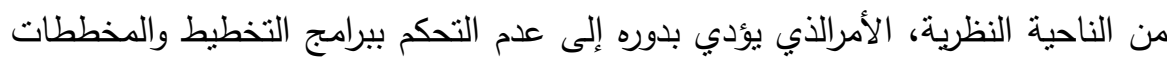

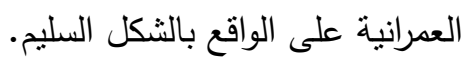
ونستنتج مما سبق أن وجود قانون موحد للتخطيط العمراني يعتبر حاجة ملحة وضرورية، خاصة مع وجود العديد من الجهات التي تمارس سلطة التخطيط العمراني.

\section{اللزوكيايت}

() العمل على إصدار قوانين أو تشريعات جديدة مستحدثة أو مكملة للتشريعات المتواجدة

$$
\text { بما يخدم المجتمع وسد متطلباته. }
$$

r) تهيئة كوادر مختصة واشراك التخصصات القانونية والادارية وتفعيل دور القوانين عند

المؤسسات التي تعنى بتخطيط المدن وتوزيع أستعمالات الارض ولما لها من دور مهم من القوانين والانظمة التي لولاها لما تدار الددن ولاتتواجد فيها تتظيم عمراني، ولأن التنظيم العمرانى لأى مدينة يعكس حضارتها. 
r) تقعيل الدور النتريعي ونتميته بما يخدم المجتمع وسد متطلبات النمو والتطور الذي يواكب

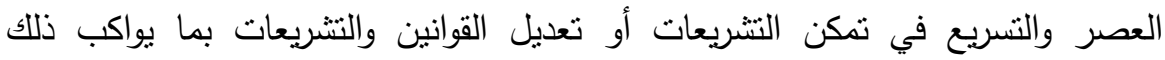

$$
\text { التطور - }
$$

§) تفعيل دور القوانين عند مفردات المنهجية في المواد التي تدرس كلاً من الاختصاصات الهندسية المختصة بالتخطيط كالهندسة المعمارية والمدنية وتخطيط المدن والبيئة وغيرها والتخصصات القانونية والاجتماعية وبعض التخصصات الإنسانية كالإدارة والإقتصاد والجغرافية وغيرها والاهتمام بهذه المفردات وشموليتها وإبراز دورها في تتظيم المدن

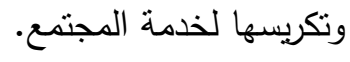

0) اشرالك المختصين والكفاءات العملية والعلمية مباشرة بالاعمال المحلية مع القوانين والخبراء في هذا المجال عند نص قانون، والاسراع بتشريعة لا كما يعمل به الآن يكتب ويصادق بله

$$
\text { ويترك حينا من الزمن. }
$$

T) ابراز دور القوانين والتتريعات واعطائها أهمية بتطبيقيها من قبل الدوائر المعنية بذلك وإنشراك المجتمع ومنظمات المجتمع المدني بتوعيته بتطبيق تلك القوانين. V الاستفادة من القوانين الدول الغربية وتسييرها بما يخدم البيئة المصرية.

\section{المرالم:}

أحمد خالد علام(7 917 (م): التشريعات المنظمة للعمر ان، مكتبة الأنجلو المصرية.

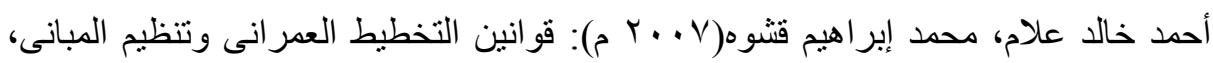
مكتبة الأنجلو المصرية الطبعة الثانية.

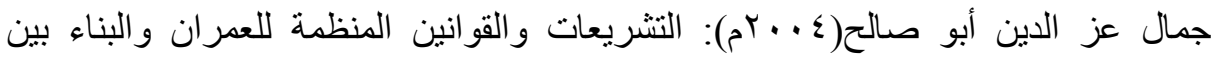

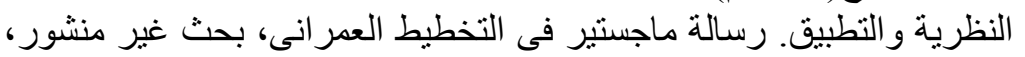

$$
\text { كلية الهندسة، جامعة القاهرة. }
$$

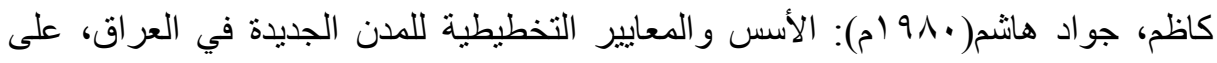

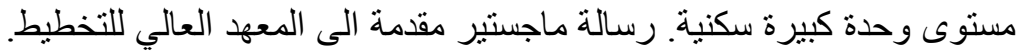

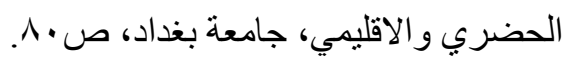

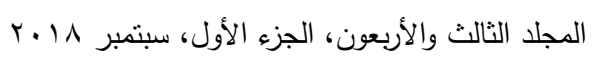




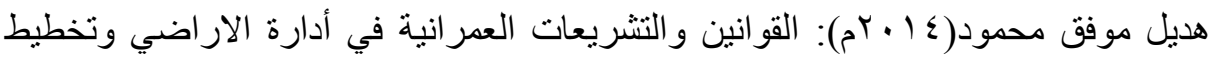

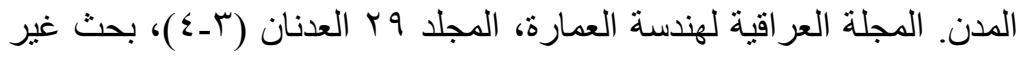

$$
\text { منشور. }
$$

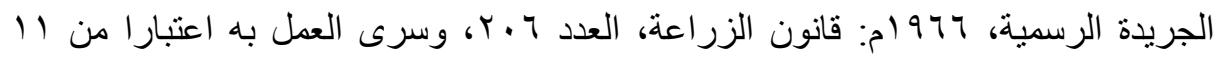

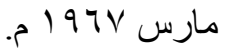

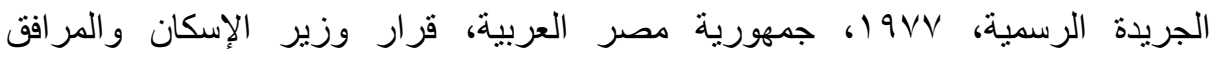

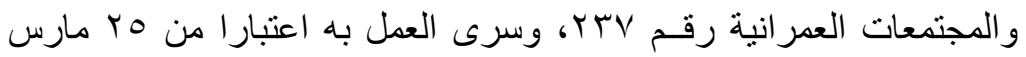

$$
\text { . } 19 \vee \wedge
$$

$$
\begin{aligned}
& \text { الجريدة الرسمية، الو (م، صدر برئاسة الجمهورية، قانون رقم (0ب ا لسنة (191 (م). }
\end{aligned}
$$

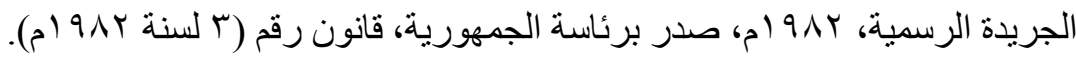

$$
\begin{aligned}
& \text { الجريدة الرسمية، • 99 (م، صدر برئاسة الجمهورية، قانون رقم (• ( لسنة • 99 (1). }
\end{aligned}
$$

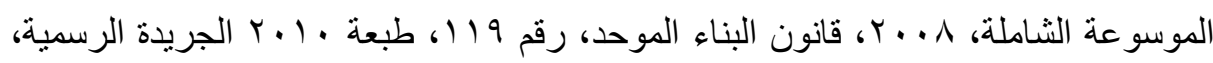

$$
\text { العدد } 9 \text { أمكرر (أ). }
$$

http://lawegypt.blogspot.com.eg/2010/10/10-1990.html

http://lawegypt.blogspot.com.eg/2010/10/119-2008.html

https://www.youm7.com/story/2018/2/9/

https://www.facebook.com/permalink.php?id=562286460486906\&stor y_fbid=565097690205783

http://kenanaonline.com/users/ibrahimkhali1/posts/521877. 


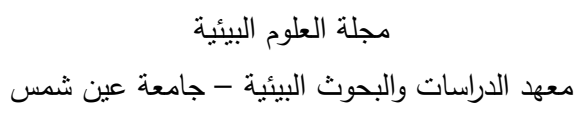

\title{
LAWS AND REGULATIONS GOVERNING THE EGYPTIAN URBAN AREAS AND SHORTCOMINGS
}

Riad, M. A.

Architectural Engineering Department, Faculty of Engineering, Helwan

University

\begin{abstract}
This study deals with the laws and legislations governing urbanization in terms of the definition of urbanization legislation, the relationship between the parties involved in planning, and the early laws that regulate urbanization beginning in 1883 with the establishment of administrative councils which are concerned with the maintenance of streets, squares and parks. (No. 52 of 1940) and amended to become part of the Urban Planning Law No. (3) of 1982, in addition to Law No. 51 of 1940 on the Regulation of Buildings and Law No. 53 of 1966 regarding the prohibition of the bulldozing of agricultural land and the Law (106 of 1976) and its amendments (Law No. 3 of 1982), which is the first law to establish the general policy and prepare the urban development plans at the level of the Republic and the general plans for the cities and villages, detailed plans and requirements. Which must be available when dividing the land and determine the body entrusted with the preparation of studies necessary for the development work, and then dealt with the unified construction law No. (119 of 2008), which defines areas of re-planning as areas subject to land use modification when preparing the general strategic plan for the city or village or outline, and procedures for the preparation and approval of the outline of the re-planning area and negotiation procedures with owners of real estate And the land within the area of modification of use, re-planning and the tasks of the committees of inventory and negotiation, and evaluation committees, and then dealt with the penalties imposed by the law for buildings that violate the provisions of the law and the infringement of agricultural land and the
\end{abstract}

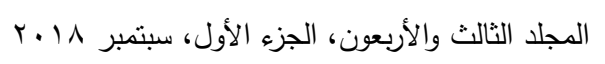


محمد أحمد رياض

lack of executive and supervisory bodies supervising $\mathrm{Z}$ movement of urbanization.

Key words: Laws and legislations governing urbanization, urban legislation, planning legislation, shortcomings in urban legislation. 